\title{
Radiative forcing by aerosols as derived from the AeroCom present-day and pre-industrial simulations
}

\author{
M. Schulz ${ }^{1}$, C. Textor ${ }^{1}$, S. Kinne ${ }^{2}$, Y. Balkanski ${ }^{1}$, S. Bauer ${ }^{3}$, T. Berntsen ${ }^{4}$, T. Berglen ${ }^{4}$, O. Boucher ${ }^{5,11}$, F. Dentener ${ }^{6}$, \\ S. Guibert ${ }^{1}$, I. S. A. Isaksen ${ }^{4}$, T. Iversen ${ }^{4}$, D. Koch ${ }^{3}$, A. Kirkevåg ${ }^{4}$, X. Liu ${ }^{7,12}$, V. Montanaro ${ }^{8}$, G. Myhre ${ }^{4}$, \\ J. E. Penner ${ }^{7}$, G. Pitari ${ }^{8}$, S. Reddy $^{9}$, Ø. Seland ${ }^{4}$, P. Stier $^{2}$, and T. Takemura ${ }^{10}$ \\ ${ }^{1}$ Laboratoire des Sciences du Climat et de l'Environnement, CEA-CNRS-UVSQ, Gif-sur-Yvette, France \\ ${ }^{2}$ Max-Planck-Institut für Meteorologie, Centre for Marine and Atmospheric Sciences (ZMAW), Hamburg, Germany \\ ${ }^{3}$ Columbia University, GISS, New York, USA \\ ${ }^{4}$ University of Oslo, Department of Geosciences, Oslo, Norway \\ ${ }^{5}$ Hadley Centre, Met Office, Exeter, UK \\ ${ }^{6}$ European Commission, Joint Research Centre, Institute for Environment and Sustainability,Climate Change Unit, Ispra, Italy \\ ${ }^{7}$ Department of Atmospheric, Oceanic and Space Sciences, University of Michigan, Ann Arbor, MI, USA \\ ${ }^{8}$ Dipartimento di Fisica, Università degli Studi L'Aquila, Coppito, Italy \\ ${ }^{9}$ NOAA, Geophysical Fluid Dynamics Laboratory, Princeton, New Jersey, USA \\ ${ }^{10}$ Research Institute for Apllied mechanics, Kyushu University, Fukuoka, Japan \\ ${ }^{11}$ Laboratoire d'Optique Atmospherique, Université des Sciences et Technologies de Lille, CNRS, Villeneuve d'Ascq, France \\ ${ }^{12}$ Battelle, Pacific Northwest National Laboratory, Richland, WA, USA
}

Received: 25 April 2006 - Published in Atmos. Chem. Phys. Discuss.: 22 June 2006

Revised: 17 October 2006 - Accepted: 22 October 2006 - Published: 16 November 2006

\begin{abstract}
Nine different global models with detailed aerosol modules have independently produced instantaneous direct radiative forcing due to anthropogenic aerosols. The anthropogenic impact is derived from the difference of two model simulations with prescribed aerosol emissions, one for present-day and one for pre-industrial conditions. The difference in the solar energy budget at the top of the atmosphere (ToA) yields a new harmonized estimate for the aerosol direct radiative forcing (RF) under all-sky conditions. On a global annual basis RF is $-0.22 \mathrm{Wm}^{-2}$, ranging from +0.04 to $-0.41 \mathrm{Wm}^{-2}$, with a standard deviation of $\pm 0.16 \mathrm{Wm}^{-2}$. Anthropogenic nitrate and dust are not included in this estimate. No model shows a significant positive all-sky RF. The corresponding clear-sky RF is $-0.68 \mathrm{Wm}^{-2}$. The cloud-sky RF was derived based on all-sky and clear-sky RF and modelled cloud cover. It was significantly different from zero and ranged between -0.16 and $+0.34 \mathrm{Wm}^{-2}$. A sensitivity analysis shows that the total aerosol RF is influenced by considerable diversity in simulated residence times, mass extinction coefficients and most importantly forcing efficiencies (forcing per unit optical depth). The clear-sky forcing efficiency (forcing per unit optical depth) has diversity comparable to that for the all-sky/ clear-sky forcing ratio. While the diversity in clear-sky forcing efficiency is impacted by factors
\end{abstract}

Correspondence to: M. Schulz

(michael.schulz@cea.fr) such as aerosol absorption, size, and surface albedo, we can show that the all-sky/clear-sky forcing ratio is important because all-sky forcing estimates require proper representation of cloud fields and the correct relative altitude placement between absorbing aerosol and clouds. The analysis of the sulphate RF shows that long sulphate residence times are compensated by low mass extinction coefficients and vice versa. This is explained by more sulphate particle humidity growth and thus higher extinction in those models where short-lived sulphate is present at lower altitude and vice versa. Solar atmospheric forcing within the atmospheric column is estimated at $+0.82 \pm 0.17 \mathrm{Wm}^{-2}$. The local annual average maxima of atmospheric forcing exceed $+5 \mathrm{Wm}^{-2}$ confirming the regional character of aerosol impacts on climate. The annual average surface forcing is $-1.02 \pm 0.23 \mathrm{Wm}^{-2}$. With the current uncertainties in the modelling of the radiative forcing due to the direct aerosol effect we show here that an estimate from one model is not sufficient but a combination of several model estimates is necessary to provide a mean and to explore the uncertainty.

\section{Introduction}

Anthropogenic aerosols modify the Earth radiation budget such that flux changes can be observed by satellites (Bellouin

Published by Copernicus GmbH on behalf of the European Geosciences Union. 
et al., 2005). Their increased presence since pre-industrial times is suspected to have partly offset global warming in the 20th century (Charlson et al., 1992). This in turn would be responsible for additional climate warming if aerosols were removed in the future through abatement of aerosol related air pollution (Anderson et al., 2003). There is also a suggestion that aerosol forcing has an important regional impact on weather and climate (Menon et al., 2002). Reduced incoming radiation observed at surface level, called global dimming, was associated with the effect of aerosols (Liepert et al., 2004; Stanhill and Cohen, 2001).

Considerable uncertainty in the radiative forcing by the different anthropogenic aerosol components has been summarized by IPCC, 2001. The need to integrate the aerosol effects on a global scale has given rise in recent years to the development of models, in which aerosol modules gained considerable complexity (Ghan, 2001; Liao et al., 2004; Martin et al., 2004; Stier et al., 2005). However, models still suffer from difficulties in representing the aerosol physics in a sufficiently coherent and complex way so as to reproduce all aspects observed with a wide range of aerosol instruments. The model inter-comparison within the framework of the AeroCom initiative (http://nansen.ipsl.jussieu.fr/AEROCOM/) has revealed important differences in describing the aerosol life cycle at all stages from emission to optical properties (Kinne et al., 2006; Textor et al., 2006).

Here we present the results of a joint study of AeroCom models with the aim of deriving a state-of-the-art best guess for the direct radiative forcing (RF) attributable to anthropogenic aerosol. With the additional diagnostics available in AeroCom we also aim to analyze the differences in RF between models. Note, this RF does not include indirect forcing contributions by aerosol induced changes to clouds and the hydrological cycle. The RF collected here lacks the contributions from anthropogenic nitrate and dust. Two experiments were performed by each of the models based on predefined emission datasets assumed to be representative for pre-industrial times at about 1750 ("AeroCom PRE") and for the year 2000 ("AeroCom B") and in principal fixed meteorological fields representing the year 2000. The difference in radiative energy balance between both experiments defines the impact due to anthropogenic aerosol. This definition also captures the effect of any non-linear aerosol dynamics, when anthropogenic aerosol interacts with the natural aerosol background, and when the anthropogenic components itself are present to a varying degree in present and pre-industrial situations. Such interactions are simulated in varying degree of complexity by the nine models as detailed by Textor et al. (2006). We note finally here that in this study we prescribed the emissions: the uncertainties in the emission datasets would add to the over-all uncertainty of our RF calculation.

\section{Model simulations}

\subsection{Experimental setup}

The analysis of the model results in this study builds on an open call to aerosol modelling groups to contribute to the AeroCom initiative. Three joint experiments (A, B, PRE) have been performed within AeroCom. The original model versions (experiment A) had not included a RF diagnostic but are documented in detail with respect to the aerosol life cycle and optical properties by Kinne et al. (2006) and Textor et al. (2006). Here we analyse the other two simulations where aerosol emissions have been prescribed for current (experiment B) and pre-industrial conditions (experiment PRE). Otherwise these experiments should not differ from A, but included additional diagnostics on RF. Groups were asked to provide output according to a protocol available on the AeroCom website (http://nansen.ipsl.jussieu.fr/AEROCOM/ protocol.html). Nine (of the sixteen) AeroCom models contributed their RF results for experiments B and PRE along with the diagnostics retrieved already for experiment A. Table 1 lists the models, their abbreviations and references to publications that provide more detail. Initial checks of the received output were conducted via an interactive website open to the public (http://nansen.ipsl.jussieu.fr/AEROCOM/ data.html). The parameters gathered comprise daily values for RF at the top of the atmosphere and at the surface, plus associated data on aerosol properties (mass loading, optical depth, size, absorption, single scattering albedo, altitude, component mass extinction efficiencies) and on environmental properties (solar surface albedo and cloud distribution). For both experiments AeroCom B and AeroCom PRE the modelers were asked to use a priori the analyzed meteorological fields for the year 2000 to either drive or nudge their model. This was done to obtain results corresponding to the AeroCom A experiment, where modelers used emissions of their choice, and which were analyzed in the above mentioned overview publications. The two participating models without nudging capability (UIO_GCM and ULAQ) established climatological means based on a 5-year simulation after a spin-up period of one year.

As has been done already in Textor et al. (2006), we define model diversity as the standard deviation among the model results. This allows to easily compare the results with those from Textor et al. (2006). Note our estimate of the standard deviation is based on only 9 AeroCom models. In addition to analysing the nine AeroCom model results incorporated in the present study on their original grid we also present figures from an average AeroCom model, constructed from the outputs of the nine models. For this purpose only the original data were re-gridded by interpolation to a common grid of horizontal resolution of $1 \times 1$ degree latitude/longitude. A local diversity diagnostic at any grid point is calculated as the standard deviation from the values of the nine models. 
Table 1. Model names and corresponding models and version names, their resolution used here and selected principal publications associated to each model. See also Textor et al. (2006) for more complete descriptions of the models. "*” signifies a climatological model was run for a five year period. All other models are driven by analysed meteorological fields (nudged climate model or chemical transport model).

\begin{tabular}{llccl}
\hline Model & Model type and version & Resolution & Levels & References \\
\hline UMI & CTM IMPACT & $2.5^{\circ} \times 2^{\circ}$ & 30 & $\begin{array}{l}\text { (Liu et al., 2005) } \\
\text { (Liu and Penner, 2002) }\end{array}$ \\
UIO_CTM & CTM OsloCTM2 & $2.81^{\circ} \times 2.81^{\circ}$ & 40 & $\begin{array}{l}\text { (Berglen et al., 2004) } \\
\text { (Myhre et al., 2003) }\end{array}$ \\
LOA & GCM LMDzT 3.3 & $3.75^{\circ} \times 2.5^{\circ}$ & 19 & $\begin{array}{l}\text { (Reddy and Boucher, 2004) } \\
\text { (Reddy et al., 2005b) }\end{array}$ \\
LSCE & GCM LMDzT 3.3-INCA & $3.75^{\circ} \times 2.5^{\circ}$ & 19 & (Textor et al., 2006) \\
MPI_HAM & GCM ECHAM5.3-HAM & $1.8^{\circ} \times 1.8^{\circ}$ & 31 & (Stier et al., 2005) \\
GISS & GCM model E & $5^{\circ} \times 4^{\circ}$ & 20 & (Koch, 2001; Koch et al., 2006) \\
UIO_GCM & GCM* CCM3.2 & $2.81^{\circ} \times 2.81^{\circ}$ & 18 & (Iversen and Seland, 2002) \\
SPRINTARS & GCM CCSR/NIES/FRCGC & $1.1^{\circ} \times 1.1^{\circ}$ & 20 & (Tirkevag and Iversen, 2002) \\
& SPRINTARS 5.7b & & & (Takemura et al., 2002, 2005) \\
ULAQ & CTM* ULAQ & $22.5^{\circ} \times 10^{\circ}$ & 26 & (Pitari et al., 2002) \\
\hline
\end{tabular}

The interpolation served also for comparison to satellite data products shown e.g. in Kinne et al. (2006).

\subsection{AeroCom emission datasets}

Inventories for global emissions of aerosol and pre-cursor gases for the years 2000 (current conditions) and 1750 (preindustrial conditions) were established based on available data in 2003. All emissions data-sets are available via a file transfer site at the Joint Research Center (JRC), Italy: $\mathrm{ftp} / / / \mathrm{ftp}$.ei.jrc.it/pub/Aerocom/. Here, we give a very brief description and the reader is referred to (Dentener et al., 2006) for more detailed information. Dust, sea-salt, sulphur components and carbonaceous aerosol emissions are provided at a spatial resolution of $1^{\circ} \times 1^{\circ}$. Temporal resolution ranges from daily for dust, sea salt and DMS to yearly for the remaining constituents. The injection altitudes and the size of the injected particles of emissions are prescribed. Aerosol emissions are categorized by its origin into "natural" and "anthropogenically modified". Natural emissions of sea-salt, dust, DMS, secondary organic aerosol and volcanic activity are assumed identical for current and pre-industrial conditions. Anthropogenically modified emissions consider contributions to sulphur (S), Particulate Organic Matter (POM) and Black (or elementary) Carbon (BC) from large scale wild-land fires (partly natural), bio fuel burning and fossil fuel burning. For pre-industrial times contributions from wild-land fires (open burning) and biofuel emissions are reduced and fossil fuels emissions are ignored. In summary we assume anthropogenic emissions for black carbon of
$6.32 \mathrm{Tg} /$ year, for particulate organic matter of $32.5 \mathrm{Tg} /$ year and for sulphur dioxide of $100.9 \mathrm{Tg}-\mathrm{SO}_{2} /$ year.

2.3 Model simulation of the anthropogenic components and forcing

The RF calculations analysed in this study involve nine different model environments with respect to the complexity of the aerosol modules and associated global circulation models. While the reader is encouraged to explore publications describing the individual models (see Table 1) together with the initial AeroCom papers from Textor et al. (2006) and Kinne et al. (2006), we consider it necessary here to document some of the differences in the RF calculation.

$\mathrm{RF}$ is defined as "the change in net (down minus up) irradiance (solar plus long-wave; in $\mathrm{Wm}^{-2}$ ) at the tropopause AFTER allowing for stratospheric temperatures to readjust to radiative equilibrium, but with surface and tropospheric temperatures and state held fixed at the unperturbed values", which is exerted by the introduction of a perturbing agent (Ramaswamy et al., 2001). For most aerosol constituents stratospheric adjustment has little effect on the RF, and the instantaneous RF at the top of the atmosphere (ToA) can be substituted for the stratospheric-adjusted RF. AeroCom RF results refer to ToA-RF. With respect to the flux perturbation by the anthropogenic aerosol we suggest here that the unperturbed state is characterized by experiment AeroCom-PRE. The analysis of the RF differences between models requires that we also retrieve the anthropogenic perturbation for several other parameters. This has been obtained by subtracting 
AeroCom-PRE from AeroCom-B simulation results. Since these are the only useful parameter values to be compared to $\mathrm{RF}$ we omit for simplicity in the remainder the specification "anthropogenic" for parameters. "Load" thus refers just to the anthropogenic load, if not mentioned otherwise.

Note that the RF derived from the AeroCom simulations does not include anthropogenic nitrate and dust, since they are not considered in the AeroCom emission database. Nitrate RF has been suggested to range between -0.03 and $-0.22 \mathrm{Wm}^{-2}$ (Jacobson, 2001a; Adams et al., 2001; Liao and Seinfeld, 2005). Dust RF is potentially more important, if the anthropogenic fraction of dust would be large. Estimates for it range from 0\% to 50\% (Tegen and Fung, 1995; Mahowald and Luo, 2003; Mahowald et al., 2004; Tegen et al., 2004; Moulin and Chiapello, 2004). The radiative effect of anthropogenic dust would be important if the dust radiative effect would be largely different from zero. However, the partial absorbing nature of dust particles is difficult to quantify and adds important uncertainty to any dust RF estimate (e.g., Haywood et al., 2003; Kaufman et al., 2001; Coen et al., 2004; Huebert et al., 2003; Clarke et al., 2004; Balkanski et al., 2006).

The omission of anthropogenic dust, of which the sources and optical properties are very uncertain, simplifies the RF calculations in that only solar broadband flux changes need to be considered. Recent work (by Reddy et al., 2005a) suggests that significant flux changes in the infrared part of the spectrum do not occur in the absence of mineral dust, essentially because anthropogenic aerosol other than dust is submicron in size. RF results reported here are for the shortwave spectrum only.

A conceptual difference among models in obtaining RF of the anthropogenic aerosol and its components is the choice of the unperturbed reference state. Internal mixing and other interactions between aerosol components affect size distribution and hygroscopicity and result in interdependencies between e.g. the sulphate RF and the black carbon RF. For the total aerosol RF a reference state with natural background aerosol is preferred over a no-aerosol reference. The experimental set-up ("B"-“PRE") establishes this type of a natural aerosol reference, and it guarantees comparability among models for the total anthropogenic (direct aerosol) impact. However, the exact procedure on how to retrieve aerosol component RF differs in between models. One way would be to isolate the perturbation due to a single component by an additional experiment, in addition to "B" and "PRE", where the target component is absent. MPI_HAM simulations refer to five experiments on top of a present day reference case to identify separately the RF of sulphate, biomass burning, total carbonaceaous aerosol, fossil fuel carbonaceous aerosol and total aerosol. Another solution was chosen in UIO_GCM where the contribution from BC, POM, $\mathrm{BC}+\mathrm{POM}$ and sulphate are removed in two more experiments per species from both present day and pre-industrial simulations. RF is then the difference between two pairs of simulation: $\mathrm{RF}_{\mathrm{x}}=(\mathrm{B}-\mathrm{PRE})-\left(\mathrm{B}_{-\mathrm{x}}-\mathrm{PRE} \mathrm{-x}_{\mathrm{x}}\right)$. Most models do not try to account for non-linear effects resulting from the aerosol mixing state and the impact it has on optical properties and computed the RF of individual components from aerosol component fields established in experiment $\mathrm{B}$ against the Reference case PRE. It is beyond the scope of this paper and not documented in the AeroCom dataset how the nonlinear effects of aerosol mixing influence the RF results. See for further discussion e.g. Jacobson (2001a), Kirkevåg and Iversen (2002), Liao and Seinfeld (2005), Stier et al. (2006a), and Stier et al. (2006b). The consequences of the different ways of describing a reference state are difficult to estimate without dedicated experiments in a single model. The results summarised here involve both model diversity with respect to aerosol properties and RF calculation concept.

Finally, for completeness and also comparability with published data, we document here deviations from the general methodology described above or from work in publications cited e.g. in Table 1. Note that these deviations are model specific and due rather to technical problems when setting up the AeroCom experiment. The following is thus more a listing and consequences for this study are thought to be small. Since the overall average for these values was negligible they were simply removed from consideration. Deviating from AeroCom experiment A the SPRINTARS model treated black carbon (BC) and particulate organic matter (POM) as external mixture. As compared to experiment $\mathrm{A}$ this resulted in lower solubility of the BC and thus extended BC lifetime. The GISS model simulated different concentration fields for natural aerosol (dust and sea-salt) in the two simulations (B and PRE) because heterogeneous concentrations changed e.g. the solubility of dust. This difference was not considered here as contributing to the "anthropogenic" RF term. Natural aerosols differ for the MPI_HAM model, where emissions of natural aerosol, in place of AeroCom suggestions, were implemented via an interactive source. The UIO_GCM model used prescribed sea salt and dust fields (Kirkevåg et al., 2005). The ULAQ model reports only clear sky forcing. The all-sky forcing in ULAQ was assumed to be $30 \%$ of the clear-sky value (assuming 70\% cloud cover and no aerosol forcing in cloudy conditions). The underlying assumption of zero RF in cloudy conditions may be likely wrong if the clear-sky RF is relatively weak and negative globally and positive in large regions. The positive forcing may be magnified, not reduced in cloudy conditions. However, looking at the other models with complete information reveals that out of 7 models, 3 suggest negative and 4 neutral or slightly positive cloud-sky-forcing. There is no consensus on the sign of this term of RF. Without further calculations available, we believe that retrieving an all-sky forcing for ULAQ this way serves comparability, even though its use is limited. Note also that the AeroCom average estimate for RF would change just slightly from -0.219 to $-0.216 \mathrm{Wm}^{-2}$ if we would omit the ULAQ-RF results. 
Table 2. Sulphate aerosol forcing related global mean values, derived from recent publications (Models A-L) and from this studies AeroCom simulations, using identical emissions (Models M-U). All values refer to the anthropogenic perturbation of atmospheric sulphur. "CheProdSO 4 /Emi-SO $\mathrm{SO}_{2}$ : Chemical production of aerosol sulphate over sulphur-emission, both in terms of sulphur mass; "Life time": derived from sulphate burden and chemical production; "MEC": mass extinction coefficient derived from dry load and sulphate aerosol optical depth; " $\tau_{\mathrm{aer}-\text { so4 }}$ and $\tau_{\mathrm{aer}-\text { so4 }}$ anthrop.": anthropogenic sulphate aerosol optical depth and its fraction of present day sulphate optical depth; "RF": shortwave radiative forcing; "NRFM": normalized RF per load; "NRF": normalized RF per unit $\tau_{\text {aer-so4 }}$.

\begin{tabular}{|c|c|c|c|c|c|c|c|c|c|c|c|}
\hline No & Model & $\begin{array}{c}\text { CheProd } \\
\mathrm{SO}_{4} / \\
\mathrm{Emi}^{-} \mathrm{SO}_{2}\end{array}$ & $\begin{array}{c}\text { Life time } \\
\mathrm{SO}_{4} \\
\text { [days] }\end{array}$ & $\begin{array}{c}\text { Load } \\
{\left[\mathrm{mg} \mathrm{SO}_{4}\right.} \\
\left.\mathrm{m}^{-2}\right]\end{array}$ & $\begin{array}{c}\mathrm{MEC} \\
{\left[\mathrm{m}^{2} \mathrm{~g}^{-1}\right.} \\
\left.\mathrm{SO}_{4}\right]\end{array}$ & $\tau_{\text {aer-so } 4}$ & $\begin{array}{c}\tau_{\text {aer-so }} 4 \\
\text { anthrop. } \\
{[\%]}\end{array}$ & $\begin{array}{c}\mathrm{RF} \\
{\left[\mathrm{Wm}^{-2}\right]}\end{array}$ & $\begin{array}{c}\text { NRFM } \\
{\left[\mathrm{Wg}^{-1}\right]}\end{array}$ & $\begin{array}{c}\text { NRF } \\
{\left[\mathrm{Wm}^{-2}\right.} \\
\left.\tau_{\mathrm{aer}}^{-1}\right]\end{array}$ & Reference \\
\hline A & CCM3 & & & 2.23 & & & & -0.56 & -251 & & (Kiehl et al., 2000) \\
\hline B & GEOSCHEM & & & 1.53 & & 0.018 & & -0.33 & -216 & -18 & (Martin et al., 2004) \\
\hline $\mathrm{C}$ & GISS & & 5.2 & 3.30 & & 0.022 & & -0.65 & -197 & -30 & (Koch, 2001) \\
\hline $\mathrm{D}$ & GISS & & & 3.27 & & & & -0.96 & -293 & & (Adams et al., 2001) \\
\hline $\mathrm{E}$ & GISS & & & 2.12 & & & & -0.57 & -269 & & (Liao and Seinfeld, 2005) \\
\hline $\mathrm{F}$ & SPRINTARS & $51 \%$ & 3.7 & 1.55 & 9.7 & 0.015 & $72 \%$ & -0.21 & -135 & -14 & (Takemura et al., 2005) \\
\hline G & LMD & & & 2.76 & & & & -0.42 & -152 & & (Boucher and Pham, 2002) \\
\hline $\mathrm{H}$ & LOA & & & 3.03 & & 0.030 & & -0.41 & -135 & -14 & (Reddy et al., 2005a) \\
\hline I & GATORG & & & 3.06 & & & & -0.32 & -105 & & (Jacobson, 2001a) \\
\hline $\mathrm{J}$ & PNNL & & & 5.50 & & 0.042 & & -0.44 & -80 & -10 & (Ghan et al., 2001) \\
\hline K & UIO_CTM & & & 1.79 & & 0.019 & & -0.37 & -207 & -19 & (Myhre et al., 2004) \\
\hline $\mathrm{L}$ & UIO_GCM & $61 \%$ & 3.6 & 2.28 & & & & -0.29 & -127 & & $(\$)$ \\
\hline M & UMI & $63 \%$ & 4.8 & 2.64 & 7.6 & 0.020 & $58 \%$ & -0.58 & -220 & -29 & This study \\
\hline $\mathrm{N}$ & UIO_CTM & $58 \%$ & 3.3 & 1.70 & 11.2 & 0.019 & $57 \%$ & -0.35 & -206 & -18 & This study \\
\hline $\mathrm{O}$ & LOA & $85 \%$ & 4.8 & 3.64 & 9.6 & 0.035 & $64 \%$ & -0.49 & -135 & -14 & This study \\
\hline $\mathrm{P}$ & LSCE & $70 \%$ & 4.9 & 3.01 & 7.6 & 0.023 & $59 \%$ & -0.42 & -140 & -18 & This study \\
\hline Q & MPI_HAM & $72 \%$ & 3.3 & 2.19 & 12.3 & 0.027 & & -0.51 & -233 & -19 & This study \\
\hline $\mathrm{R}$ & GISS & $30 \%$ & 5.1 & 1.34 & 4.5 & 0.006 & $41 \%$ & -0.19 & -142 & -32 & This study \\
\hline$S$ & UIO_GCM & $59 \%$ & 3.3 & 1.72 & 7.0 & 0.012 & $59 \%$ & -0.25 & -145 & -21 & This study \\
\hline $\mathrm{T}$ & SPRINTARS & $58 \%$ & 2.3 & 1.19 & 10.9 & 0.013 & $59 \%$ & -0.16 & -134 & -12 & This study \\
\hline $\mathrm{U}$ & ULAQ & $60 \%$ & 3.0 & 1.62 & 12.3 & 0.020 & $42 \%$ & -0.23 & -142 & -12 & This study \\
\hline \multicolumn{2}{|c|}{ Average models A-L } & & & 2.70 & & 0.024 & & -0.46 & -181 & -18 & \\
\hline \multicolumn{2}{|c|}{ Average models M-U } & $62 \%$ & 3.9 & 2.12 & 9.1 & 0.019 & $55 \%$ & -0.35 & -161 & -19 & This study \\
\hline \multicolumn{2}{|c|}{ Stddev A-L } & & & 1.09 & & 0.010 & & 0.20 & 68 & 7 & \\
\hline \multicolumn{2}{|c|}{ Stddev M-U } & $15 \%$ & 1.0 & 0.82 & 2.7 & 0.009 & $9 \%$ & 0.15 & 41 & 7 & This study \\
\hline \multicolumn{2}{|c|}{ Stddev/Avg M-U } & $24 \%$ & $27 \%$ & $39 \%$ & $29 \%$ & $44 \%$ & $16 \%$ & $44 \%$ & $24 \%$ & $36 \%$ & \\
\hline
\end{tabular}

\$ Kirkevag and Iversen, 2002; Iversen and Seland, 2002

Most probably there are other differences between models, which we are not aware of. We feel that the methodological deviations documented here illustrate the unavoidable imperfection of a model intercomparison effort but that might help to guide future research. We note also that a direct comparison to results from the two accompanying papers Textor et al. (2006) and Kinne et al. (2006) are difficult, because they refer to AeroCom A simulations and the natural and anthropogenic aerosol together, while this paper focuses on the AeroCom B and PRE experiments and the anthropogenic aerosol fraction only.

\section{Results}

\subsection{Sulphate aerosols}

Model results for anthropogenic sulphate load, aerosol optical depth (AOD, always in this paper for mid-visible wavelengths $(0.55 \mu \mathrm{m}))$ and its fraction with respect to total sulphate are summarized in Table 2. Also listed in this table are model predictions for the sulphate RF and associated forcing efficiencies, forcing with respect to sulphate load and AOD, respectively. Results of AeroCom models are found in the lower part of the table and they are compared to previous model predictions, provided in the upper part of the table. Average and standard deviation for the two groups of model results are placed at the bottom of the table to illustrate how much the coordinated AeroCom effort differs from model results found in the published literature.

The AeroCom results and previous model predictions agree that sulphate exerts a negative RF, cooling the EarthAtmosphere-System. The mean of the RF estimate from the AeroCom models $\left(-0.35 \mathrm{Wm}^{-2}\right)$ is $25 \%$ smaller than those from previous model predictions $\left(-0.46 \mathrm{Wm}^{-2}\right)$. Both sulphate burdens and optical depths are $25 \%$ smaller for the AeroCom models, suggesting that emissions could be lower in the AeroCom simulations. While we have not all informations available for the previous model predictions we can compare AeroCom A and B results. AeroCom B emissions are on average $10 \%$ less than the $\mathrm{SO}_{2}$ emissions used in experiment A. On average, among the nine models investi- 
gated here, aerosol load was almost the same between A and $\mathrm{B}$ and AOD of sulphate decreased by 5\%. Assuming that the AeroCom A set-ups resemble the previous model predictions, this suggests that the revised and regionally shifted $\mathrm{SO}_{2}$ emissions (AeroCom $\mathrm{B}$ suggests especially reductions in Europe) alone can not explain the difference between the AeroCom results and previous model predictions. Note also, that the mean forcing efficiency with respect to sulphate load (NRFM) from previous model predictions is slightly higher than that of AeroCom, but that the forcing efficiency per unit optical depth is rather similar.

However, RF results from the models still vary substantially, reflected by a significant standard deviation (ca. $40 \%$ on average) for load, AOD and RF. This diversity is larger than the difference between the averages from the two model groups. The diversity of RF among AeroCom models is only slightly smaller than that of the previous model predictions. A comparison with RF results from AeroCom A simulations is unfortunately not available. However, we can compare the AOD-diversity for the nine AeroCom models between AeroCom A as reported by Kinne et al. (2006) with their AeroCom B simulations as used here. Mean total sulphate AOD (natural and anthropogenic) and the corresponding diversity as standard deviation was very similar (A: $0.032 \pm 44 \%$ versus B: $0.030 \pm 49 \%)$. This altogether suggests that the prescribed emissions in AeroCom do not produce a significantly larger agreement among models.

The previous COSAM intercomparison stated in fact similar diversity based on 10 global aerosol models (Barrie et al., 2001) using identical emissions. GISS and MPI_HAM versions had already participated in this earlier exercise. Residence times of sulphate in the 10 models in COSAM ranged between 3.2 and 7.5 days, the range being shifted to slightly smaller values in this study (2.3 to 5.1 days). Vertical sulphate mass in COSAM was found to reside by $40-60 \%$ above $2.5 \mathrm{~km}$, while we find $50-70 \%$ of total sulphate mass above $2.5 \mathrm{~km}$, with the exception of the SPRINTARS model (25\%). While other diagnostics are difficult to compare, this indicates in very coarse manner that little further agreement on the modeling of the sulfur cycle has been achieved since COSAM.

Table 2 reports several other diagnostics, which may explain RF diversity among AeroCom models. The relative standard deviation in load (39\%) is in effect both due to the variation in efficiency (24\%), with which emitted $\mathrm{SO}_{2}$ is transformed to aerosol sulphate, and to the variation in the life time of sulphate in the atmosphere $(27 \%)$. Textor et al. (2006) discussed the difficulty to pinpoint the reasons for such diversity in the loads and conversion rates from $\mathrm{SO}_{2}$ to sulphate. The example of the LOA and LSCE simulations is interesting because very similar models are used, with an identical transport model (LMDzT) and almost identical chemical sulphate production scheme (except for dynamic oxidant levels in the LSCE-model). The difference between LOA and LSCE in chemical transformation of $\mathrm{SO}_{2}$ to aerosol sulphate ( $85 \%$ versus $70 \%$ ) is difficult to explain, because both a different dry deposition scheme of the precursor gas $\mathrm{SO}_{2}$ and the slightly different sulphate formation rates can be the cause. Another particular case is the low ammonium sulphate production in GISS, which is due to a significant loss of $\mathrm{SO}_{2}$ on mineral dust (Bauer et al., 2005). The resulting sulphate on dust is not included in the sulphate budget as shown here and is not assumed to have a significant direct radiative effect, since it only slightly alters the optical properties of dust.

On top of the sulphate load variation (39\%) the mass extinction coefficient varies by another $29 \%$ and those factors together explain that the sulphate AOD varies by $44 \%$. The anthropogenic fraction of the total sulphate AOD varies by $16 \%$, despite identical natural and anthropogenic sulphur emissions. It indicates that there are important differences in the models on the individual process level of the sulphur cycle. It is also interesting that the forcing efficiency per $\mathrm{kg}$ dry mass (NRFM) varies with $24 \%$ less than that of the forcing efficiency per unit optical depth (NRF) with $36 \%$, although optical depth should be linked more closely to RF. A refined sensitivity analysis of the impact of different factors on RF diversity, using the additional results in Table 2, is done in Sect. 3.5. Altogether the variation analysis shows that the factors which link anthropogenic sulphur emissions to RF are equally important.

\subsection{Carbonaceous aerosols}

The different chemical components that belong to the carbonaceous aerosol give rise to controversial splits of the total carbonaceous aerosol forcing. Biomass burning aerosols have been shown to be rather homogeneous in nature, internally mixed to a large extent and with lower light absorption coefficients than soot particles emitted from high temperature combustion processes. Organic matter from fossil fuel burning has been suggested to be partly externally mixed from BC particles. Secondary organic aerosol may be formed from volatile organic compound emissions without soot being necessarily present. For an overview of the state of knowledge on carbonaceous aerosols see Kanakidou et al. (2005). The three source categories, biomass burning (BB), fossil fuel black carbon (FFBC) and fossil fuel particulate organic matter (FFPOM) evidently do not fit all problems in attributing carbonaceous aerosol RF. While some models report fossil fuel and biomass burning aerosol RF separately, others use emission inventories that are already combined. To add complexity, measurements for both concentration and emission profiles often refer to an absorbing carbon component, summarised for simplicity as black carbon (BC), and a bulk chemical component, total organic carbon (TOC). TOC is recalculated to particulate organic matter (POM) by empirical conversion factors accounting for non-carbon material present. Both the measurement basis of TOC and the prevailing internally mixed particle nature suggest that the 
Table 3. Global mean values of load and optical properties of carbonaceous aerosol. All values correspond to the anthropogenic fraction. Life times are calculated from emission and load. POM: Particulate organic matter; BC: black carbon. MEC: dry mass extinction coefficient. Lines A-K: recently published model simulations; Lines L-T: Models used AeroCom emissions.

\begin{tabular}{|c|c|c|c|c|c|c|c|c|c|c|c|}
\hline No & Model & $\begin{array}{l}\text { Life time } \\
\text { POM } \\
\text { [days] }\end{array}$ & $\begin{array}{c}\text { Load } \\
\text { POM } \\
{\left[\mathrm{mg} \mathrm{m}^{-2}\right.}\end{array}$ & $\begin{array}{c}\text { MEC } \\
\text { POM } \\
{\left[\mathrm{m}^{2} \mathrm{~g}^{-1}\right]}\end{array}$ & $\begin{array}{c}\tau_{\mathrm{aer}} \\
\mathrm{POM}\end{array}$ & $\begin{array}{c}\tau_{\text {aer }} \\
\text { POM anthrop. } \\
\text { fraction }\end{array}$ & $\begin{array}{c}\text { Life time } \\
\text { BC } \\
\text { [days] }\end{array}$ & $\begin{array}{c}\text { Load } \\
\text { BC } \\
{\left[\mathrm{mg} \mathrm{m}^{-2}\right]}\end{array}$ & $\begin{array}{c}\text { MABS } \\
\text { BC } \\
{\left[\mathrm{m}^{2} \mathrm{~g}^{-1}\right]}\end{array}$ & $\begin{array}{c}\tau_{\mathrm{aer}-\mathrm{abs}} \\
\text { BC } \\
{[]^{*} 1000}\end{array}$ & Reference \\
\hline A & SPRINTARS & & & & & & & & & & (Takemura et al., 2001) \\
\hline B & LOA & & 2.33 & & 0.016 & & & 0.37 & & & (Reddy et al., 2005a) \\
\hline $\mathrm{C}$ & GISS & & 1.86 & & 0.017 & & & 0.29 & & & (Hansen and Mki. Sato, 2005) \\
\hline $\mathrm{D}$ & GISS & 3.9 & 1.86 & & 0.015 & & 4.4 & 0.29 & & & (Koch, 2001) \\
\hline $\mathrm{E}$ & GISS & & 2.39 & & & & & 0.39 & & & (Chung and Seinfeld, 2002) \\
\hline $\mathrm{F}$ & GISS & & 2.49 & & & & & 0.43 & & & (Liao and Seinfeld, 2005) \\
\hline $\mathrm{G}$ & SPRINTARS & & 2.67 & & 0.029 & $82 \%$ & & 0.53 & & & (Takemura et al., 2005) \\
\hline $\mathrm{H}$ & GATORG & & 2.55 & & & & & 0.39 & & & (Jacobson, 2001a) \\
\hline I & MOZGN & & 3.03 & & 0.018 & & & & & & (Ming et al., 2006) \\
\hline $\mathrm{J}$ & $\mathrm{CCM}$ & & & & & & & 0.33 & & & (Wang, 2004) \\
\hline $\mathrm{K}$ & UIO_GCM & & & & & & 4.6 & 0.30 & & & (Kirkevag and Iversen, 2002) \\
\hline $\mathrm{L}$ & UMI & 6.6 & 1.16 & 5.2 & 0.0060 & $53 \%$ & 5.8 & 0.19 & 6.8 & 1.29 & This study \\
\hline M & UIO_CTM & 6.4 & 1.12 & 5.2 & 0.0058 & $55 \%$ & 5.5 & 0.19 & 7.2 & 1.34 & This study \\
\hline $\mathrm{N}$ & LOA & 8.0 & 1.41 & 6.0 & 0.0085 & $52 \%$ & 7.3 & 0.25 & 8.0 & 1.98 & This study \\
\hline $\mathrm{O}$ & LSCE & 8.6 & 1.50 & 5.3 & 0.0079 & $46 \%$ & 7.5 & 0.25 & 4.4 & 1.11 & This study \\
\hline $\mathrm{P}$ & MPI_HAM & 5.8 & 1.00 & 7.7 & 0.0077 & & 4.9 & 0.16 & 7.7 & 1.23 & This study \\
\hline $\mathrm{Q}$ & GISS & 7.0 & 1.22 & 4.9 & 0.0060 & $51 \%$ & 7.2 & 0.24 & $7.6^{\#}$ & $1.83^{\#}$ & This study \\
\hline $\mathrm{R}$ & UIO_GCM & 5.0 & 0.88 & 5.2 & 0.0046 & $59 \%$ & 5.5 & 0.19 & 10.5 & 1.95 & This study \\
\hline $\mathrm{S}$ & SPRINTARS & 10.5 & 1.84 & 10.9 & 0.0200 & $49 \%$ & 10.6 & 0.37 & 9.8 & 3.50 & This study \\
\hline $\mathrm{T}$ & ULAQ & 9.8 & 1.71 & 4.4 & 0.0075 & $58 \%$ & 11.4 & 0.38 & 7.5 & 2.90 & This study \\
\hline \multicolumn{2}{|c|}{ Average A-K } & & 2.40 & & 0.019 & & & 0.37 & & & \\
\hline \multicolumn{2}{|c|}{ Average L-T } & 7.6 & 1.32 & 6.1 & 0.008 & $53 \%$ & 7.3 & 0.25 & 7.7 & 1.90 & This study \\
\hline \multicolumn{2}{|c|}{ Stddev A-K } & & 0.39 & & 0.006 & & & 0.08 & & & \\
\hline \multicolumn{2}{|c|}{ Stddev L-T } & 1.8 & 0.32 & 2.0 & 0.005 & $4 \%$ & 2.3 & 0.08 & 1.7 & 0.80 & This study \\
\hline \multicolumn{2}{|c|}{ Stddev/Avg L-T } & $24 \%$ & $25 \%$ & $33 \%$ & $56 \%$ & $8 \%$ & $31 \%$ & $32 \%$ & $23 \%$ & $43 \%$ & \\
\hline
\end{tabular}

\# GISS absorption coefficient assumed to equal that of AeroCom models $\left(7.7 \mathrm{~m}^{2} \mathrm{~g}^{-1}\right)$

three source categories mentioned above should be treated as a total carbonaceous category, which we name hereafter (BCPOM).

The AeroCom model results are heterogeneous with respect to identifying carbonaceous aerosol categories, because the model structure with respect to the split of the carbonaceous aerosols is difficult to change for just one experiment. To make the results from the different models more comparable we chose to compute the missing values. This is done based on ratios established within those models having explicitly attributed RF to a category-split of the carbonaceous particles. These ratios relate e.g. fossil-fuel BC-RF to total BC-RF (50\%), fossil-fuel POM-RF to total POM-RF (25\%). We assume linear additivity for biomass burning RF and fossil-fuel carbonaceous RF. The relations and the models on which they are based are detailed in the footnotes of Table 4. The relations derived from global mean values as reported in Table 4 should not be seen as valid on a local level.

Carbonaceous aerosol life times, loads and optical properties are found in Table 3. This table also reports AeroCom group results together with recently published data for comparison. As for sulphate, the diversity in POM load and AOD is as large among AeroCom models as in the previous model prediction result group. Results from AeroCom A and B simulations are also similar. Comparing total POM AOD from our nine models shows slightly less POM AOD in B and despite equal emissions larger diversity in B (A: $0.018 \pm 44 \%$ versus B: $0.014 \pm 64 \%$ ).

The variation in POM mass extinction coefficient is slightly more important $(33 \%)$ as compared to that of POM lifetime $(24 \%)$. The anthropogenic fraction of POM varies little $(8 \%)$ but its variation indicates significant differences in removal patterns among models, given that the emissions were prescribed. However, the anthropogenic fraction of POM-AOD varies less than that of sulphate because, in contrast, an additional process (chemical production) affects the fate of the natural and anthropogenic sulphur emissions. BC lifetime is smaller than that of POM in half of the AeroCom models (L-P). Note that the biomass burning aerosol, with a higher fraction of POM, are emitted in the AeroCom emissions at higher altitudes than fossil fuel derived emissions and mostly in the dry season (Dentener et al., 2006). However, the mass absorption coefficient of $\mathrm{BC}$ also shows considerable variation. As Kinne et al. (2006) have shown, this variation can be explained in part by the variation in aerosol composition among the models. This is probably less important in our experiments B and PRE, because BC 
Table 4. Anthropogenic aerosol forcing (RF) for different carbonaceous components: FFBC=fossil fuel black carbon, FFPOM= fossil fuel particulate organic matter, BB=biomass burning. "NRF POM": normalized RF per unit POM optical depth; "NRF BC": normalized RF per unit total absorption optical depth; Lines A-K: recently published; Lines L-T: Models used AeroCom emissions.

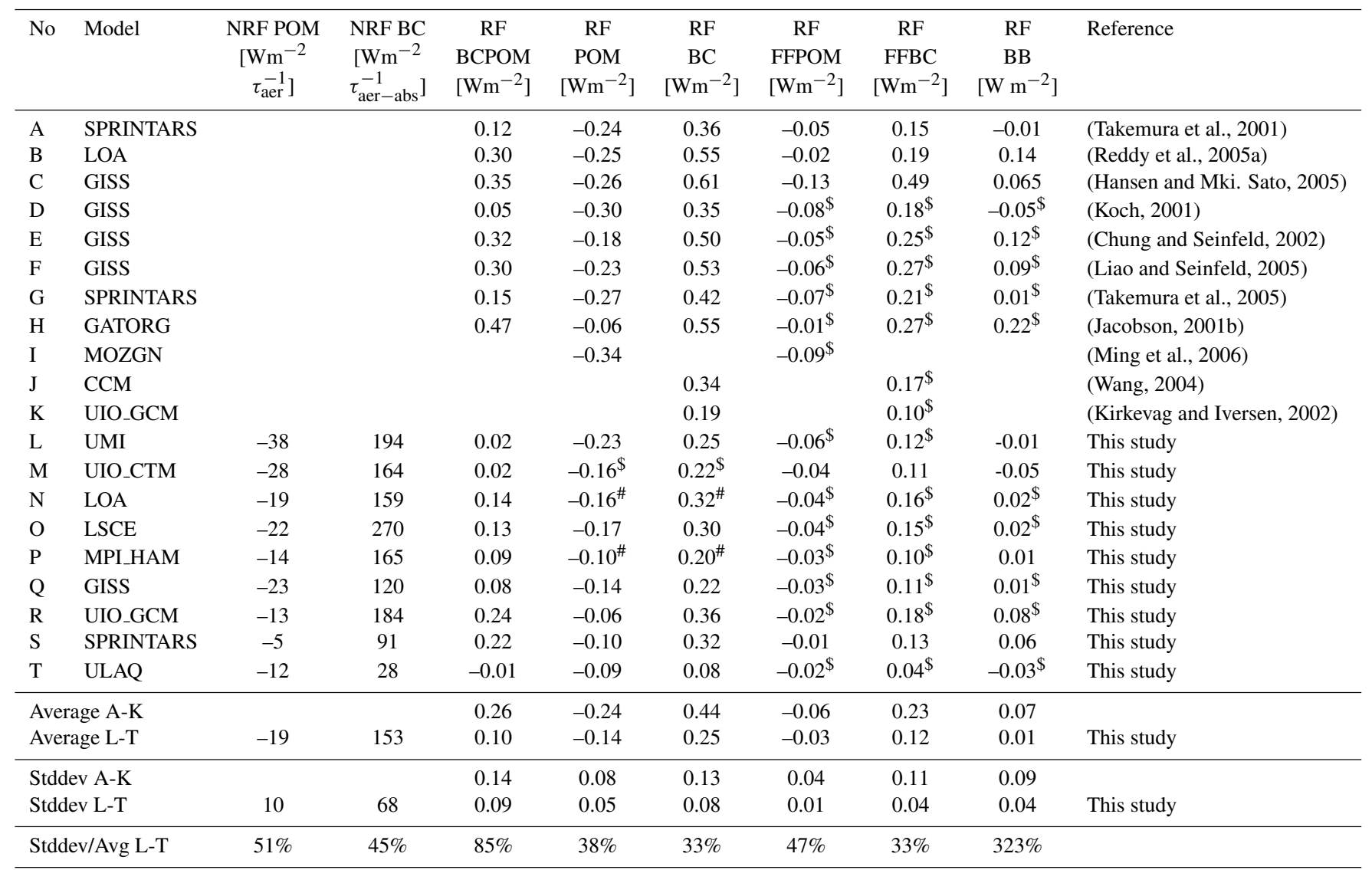

$\$$ Models $\mathrm{A}-\mathrm{C}$ are used to provide a split in sources derived from total $\mathrm{POM}$ and total $\mathrm{BC}$; $\mathrm{FFPOM=POM*0.25;} \mathrm{FFBC}=\mathrm{BC} * .5$; $\mathrm{BB}=(\mathrm{BCPOM})-(\mathrm{FFPOM}+\mathrm{FFBC}) ; \mathrm{BC}=2 * \mathrm{FFBC} ; \mathrm{POM}=4 * \mathrm{FFPOM}$

\# Models L,O,Q-T are used to provide a split in components: $\mathrm{POM}=\mathrm{BCPOM}^{*}-1.16$; $\mathrm{BC}=\mathrm{BCPOM}{ }^{*} 2.25$

and POM loads are correlated through harmonized emission fields. With absent anthropogenic dust, no dust absorption will interfere in our diagnostics here. However, assumptions on internal mixing and dependence of absorption on the presence of other aerosol components such as sulphate and aerosol water will create differences. Further investigation of the underlying assumptions in the different models is needed. We can suggest, that the optical properties of BC and POM are a source of considerable diversity among the AeroCom models with respect to RF calculations.

The corresponding RF values and forcing efficiencies are found in Table 4. The total BCPOM RF is positive (warming the Earth-Atmosphere System) for the AeroCom models and previous model predictions. As for sulphate, the BCPOM RF suggested by the AeroCom models is smaller in magnitude than that by non-AeroCom models $(+0.10$ instead of $+0.26 \mathrm{Wm}^{-2}$ ). This is consistent with smaller loads of both
$\mathrm{BC}$ and POM in the AeroCom simulations, which can partly be explained by using prescribed biomass burning emissions for the year 2000, which were relatively small compared to the average over the last decade (van der Werf et al., 2003). Also the fossil fuel inventory used in the AeroCom emission data set referring to Bond et al. (2004) is low, especially over Europe. Emissions for total POM and BC in the original AeroCom A simulations were approximately $30 \%$ higher than those prescribed for AeroCom B (Textor et al., 2006; and Dentener et al., 2006). A comparison of the average POM AOD from the nine models analysed here also shows a drop of roughly 30\% (POM AOD Exp. A: 0.0184; Exp. B: $0.0144)$. Note that the change in just the anthropogenic POM emissions can not be diagnosed due to missing information for AeroCom A.

The BCPOM RF estimates, and all other categories of carbonaceous aerosol RF, vary considerably. In light of the large 
differences for aerosol absorption among AeroCom models this is not completely surprising. Aerosol absorption makes RF calculations dependent on environmental factors, resulting in a less negative (or more positive) RF, especially when placed over highly reflective surfaces (e.g. snow, low clouds and even desert regions). In that context also spatial differences in burden distributions contribute (Fig. 1). Several models transport considerable amounts of $\mathrm{BC}$ towards the polar regions, while others are less diffusive or remove $\mathrm{BC}$ more efficiently close to emission sources (e.g. MPI_HAM and UIO_CTM). The diagnostics of long range transport is probably a good indicator of black carbon remaining at high altitudes, which in itself is a result of a less efficient washout process or an efficient vertical transport process parameterisation and differences in the treatment of black carbon ageing. An evaluation of the BC fields with measurements is beyond the scope of this paper, and will be performed in future work for the AeroCom results.

A word of caution is needed before the individual source categories of carbonaceous aerosol RF are discussed: Since gaps in the submitted model results were filled by recomputed values, the different estimates by source category (total BCPOM; total BC; total POM; fossil fuel BC: FFBC; fossil fuel POM: FFPOM and biomass burning: BB) are not completely independent of each other. There is general agreement between AeroCom and non-AeroCom models that the POM-RF is negative and that BC-RF is positive - resulting overall in a slightly positive combined BCPOM RF (on an annual global basis). Comparisons between forcings associated to biomass burning and fossil fuel burning suggest a more positive (or less negative) fossil fuel RF, which is consistent with higher BC/POM ratios for fossil fuel emissions.

The inspection of the consistency of the BCPOM-RF with the split into either BC-RF+POM-RF or into FFBC$\mathrm{RF}+\mathrm{FFPOM}-\mathrm{RF}+\mathrm{BB}-\mathrm{RF}$ reveals that the total carbonaceous aerosol RF is not always a linear combination of the two sorts of splits. This is partly due to the method used for filling gaps, where ratios established in other models are used. Secondly it expresses the difficulty in ascribing a RF to individual carbonaceous aerosol source categories. The internal aerosol mixing and associated changes in forcing efficiency of especially black carbon but also POM is responsible for non-linear effects.

The diversity in component wise RF is largest for $\mathrm{BB}$ (323\%). The component forcings of fossil fuel BC or POM and also those of total BC and POM vary between 33\% and $47 \%$. In absolute terms BB-RF shows similar variation $\left( \pm 0.04 \mathrm{Wm}^{-2}\right)$ than the fossil fuel components $( \pm 0.01-$ $\left.0.04 \mathrm{Wm}^{-2}\right)$. Variation in BCPOM RF $(85 \%)$ is significantly larger than that of the sulphate RF. Altogether the carbonaceous aerosol RF is responsible for an important part of the total RF diversity among models.

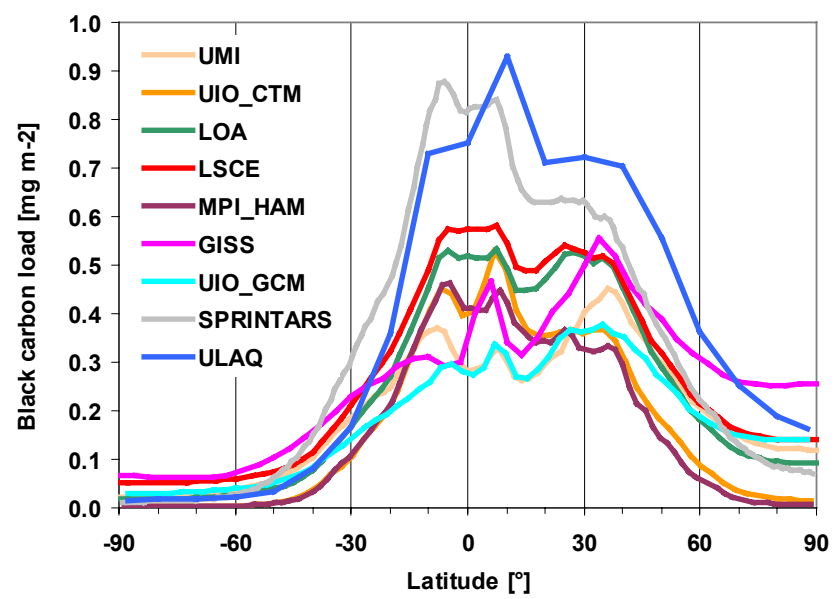

Fig. 1. Zonal distribution of the atmospheric load of black carbon for the AEROCOM B (present-day emissions) simulation.

\subsection{Total anthropogenic aerosol}

All nine AeroCom models reported a component combined total aerosol RF based on the AeroCom emissions. Note again, that nitrate, ammonium and anthropogenic dust are not considered in AeroCom emissions. However, ammonium sulphate is implicitly assumed when deriving sulphate optical parameters (except for nucleation derived sulphate in e.g. UIO_GCM). The RF values can be found in Table 5 along with global annual averages for aerosol load (or mass) and aerosol optical depth (AOD) and further diagnostics of the aerosol RF. The anthropogenic AOD fraction (of only $25 \% \pm 11 \%$ globally) leads to a negative all-sky RF of $-0.22 \mathrm{Wm}^{-2}$ and a cooling of the EarthAtmosphere-System, that is an order of magnitude smaller than the warming attributed to the anthropogenic enhancement of green-house gas concentrations. Based on just these results, in the light of a low standard deviation of $\pm 0.16 \mathrm{Wm}^{-2}$, an overall warming by aerosol is unlikely. The non-AeroCom models show a similar RF and standard deviation of $-0.20 \pm 0.21 \mathrm{Wm}^{-2}$. However, additional uncertainty due to emissions and other forcing terms (such as the indirect forcing, nitrate and dust) need to be added to obtain the overall aerosol RF and its uncertainty.

The relatively small cooling due to the direct aerosol RF is the result of warming of the $\mathrm{BC}$ containing components and opposite cooling by POM and sulphate, as illustrated in Fig. 2. An explanation for the relatively small standard deviation of the total aerosol RF is that the magnitude of negative (POM) and positive (BC) forcing is correlated. Their RF is correlated, because the residence times of the carbonaceous aerosol components in a given model are already connected. The correlation coefficient between BC and POM residence times from nine AeroCom models is 0.92 .

Figure 3 shows the zonal distribution of the total aerosol $\mathrm{RF}$ in the nine AeroCom models. Most of the (negative) RF 
Table 5. AeroCom (models H-P) and recent other model estimates (A-G) simulation results of anthropogenic aerosol load, anthropogenic aerosol optical depth $\left(\tau_{\text {aer }}\right)$, its fraction of present day total aerosol optical depth ( $\tau_{\text {aer }}$ anthrop. $)$, a dry mass extinction coefficient $($ MEC) as well as cloud cover and clear-sky forcing efficiency per unit AOD. The all-sky total aerosol direct radiative forcing RF values are accompanied by the clear-sky and cloud-sky components together with their ratio. Solar surface forcing and solar atmospheric forcing are given for all-sky conditions.

\begin{tabular}{|c|c|c|c|c|c|c|c|c|c|c|c|c|c|c|}
\hline No & Model & $\begin{array}{c}\text { Load } \\
{\left[\mathrm{mg} \mathrm{m}^{-2}\right]}\end{array}$ & $\tau_{\mathrm{aer}}$ & $\begin{array}{c}\tau_{\text {aer. }} \\
\text { anthrop } \\
\text { fraction }\end{array}$ & $\begin{array}{c}\text { MEC } \\
{\left[\mathrm{m}^{2} \mathrm{~g}^{-1}\right]}\end{array}$ & $\begin{array}{l}\text { Cloud } \\
\text { cover }\end{array}$ & $\begin{array}{c}\text { NRF } \\
\text { clear-sky } \\
{\left[\mathrm{Wm}^{-2} \tau_{\text {aer }}^{-1}\right]}\end{array}$ & $\begin{array}{c}\mathrm{RF} \\
\text { all-sky/ } \\
\text { clear-sky }\end{array}$ & $\begin{array}{l}\mathrm{RF} \text { top } \\
\text { clear sky } \\
{\left[\mathrm{Wm}^{-2}\right]}\end{array}$ & $\begin{array}{l}\text { RF top } \\
\text { cloud-sky } \\
{\left[\mathrm{W} \mathrm{m}^{-2}\right]}\end{array}$ & $\begin{array}{l}\text { RF top } \\
\text { all-sky } \\
{\left[\mathrm{Wm}^{-2}\right]}\end{array}$ & $\begin{array}{c}\text { surface } \\
\text { forcing } \\
\text { all-sky }\left[\mathrm{Wm}^{-2}\right]\end{array}$ & $\begin{array}{l}\text { Atmospheric } \\
\text { forcing } \\
\text { all-sky }\left[\mathrm{Wm}^{-2}\right]\end{array}$ & Reference \\
\hline A & GISS & 5.0 & & & & $79 \%$ & & & & & $\begin{array}{c}+0.01^{\$} \\
-0.39^{\&}\end{array}$ & $\begin{array}{l}-2.42^{\$} \\
-1.98^{\&}\end{array}$ & $\begin{array}{l}2.43^{\$} \\
1.59^{\&}\end{array}$ & (Liao and Seinfeld, 2005) \\
\hline B & LOA & 6.0 & 0.049 & $34 \%$ & & $70 \%$ & & & -0.53 & & -0.09 & & & (Reddy and Boucher, 2004) \\
\hline $\mathrm{C}$ & SPRINTARS & 4.8 & 0.044 & $50 \%$ & 9.2 & $63 \%$ & -18 & 0.08 & -0.77 & +0.36 & -0.06 & -1.92 & 1.86 & (Takemura et al., 2005) \\
\hline D & UIO_GCM & 2.7 & 0.021 & $6 \%$ & & $57 \%$ & -17 & 0.83 & -0.35 & -0.25 & -0.11 & -0.60 & -0.49 & (Kirkevag and Iversen, 2002) \\
\hline E & GATORG & 6.4 & & & & $62 \%$ & & & -0.89 & & -0.12 & -2.5 & 2.38 & (Jacobson, 2001a) \\
\hline $\mathrm{F}$ & GISS & 6.7 & 0.049 & & & & & & & & -0.23 & & & (Hansen et al., 2005) \\
\hline G & GISS & 5.6 & 0.040 & & & & & & & & -0.63 & & & (Koch, 2001) \\
\hline $\mathrm{H}$ & UMI & 4.0 & 0.028 & $25 \%$ & 7.0 & $63 \%$ & -29 & 0.51 & -0.80 & -0.10 & -0.41 & -1.24 & 0.84 & This study \\
\hline I & UIO_CTM & 3.0 & 0.026 & $19 \%$ & 8.5 & $70 \%$ & -33 & 0.40 & -0.85 & -0.07 & -0.34 & -0.95 & 0.61 & This study \\
\hline $\mathrm{J}$ & LOA & 5.3 & 0.046 & $28 \%$ & 8.7 & $70 \%$ & -18 & 0.44 & -0.80 & -0.16 & -0.35 & -1.49 & 1.14 & This study \\
\hline $\mathrm{K}$ & LSCE & 4.8 & 0.033 & $40 \%$ & 6.9 & $62 \%$ & -29 & 0.30 & -0.94 & 0.08 & -0.28 & -0.93 & 0.66 & This study \\
\hline $\mathrm{L}$ & MPI_HAM & 3.4 & 0.032 & $24 \%$ & 9.6 & $62 \%$ & -20 & 0.42 & -0.64 & 0.00 & -0.27 & -0.98 & 0.71 & This study \\
\hline M & GISS & 2.8 & 0.014 & $11 \%$ & 5.0 & $57 \%$ & -21 & 0.36 & -0.29 & 0.05 & -0.11 & -0.81 & 0.79 & This study \\
\hline $\mathrm{N}$ & UIO_GCM & 2.8 & 0.017 & $11 \%$ & 6.2 & $57 \%$ & & & & & -0.01 & -0.84 & 0.84 & This study \\
\hline $\mathrm{O}$ & SPRINTARS & 3.2 & 0.036 & $44 \%$ & 11.1 & $62 \%$ & -10 & -0.12 & -0.35 & 0.34 & +0.04 & -0.91 & 0.96 & This study \\
\hline$P$ & ULAQ & 3.7 & 0.030 & $23 \%$ & 8.1 & & -26 & & -0.79 & & -0.24 & & & This study \\
\hline \multirow{2}{*}{\multicolumn{2}{|c|}{$\begin{array}{l}\text { Average A-G } \\
\text { Average H-P }\end{array}$}} & 5.3 & 0.041 & & & $66 \%$ & & & -0.64 & & -0.20 & -1.88 & 1.55 & \\
\hline & & 3.7 & 0.029 & $25 \%$ & 7.9 & $63 \%$ & -23 & 0.33 & -0.68 & 0.02 & -0.22 & -1.02 & 0.82 & \\
\hline \multirow{2}{*}{\multicolumn{2}{|c|}{$\begin{array}{l}\text { Stddev A-G } \\
\text { Stddev H-P }\end{array}$}} & 1.3 & 0.012 & & & $9 \%$ & & & 0.24 & & 0.21 & 0.76 & 1.20 & \\
\hline & & 0.9 & 0.010 & $11 \%$ & 1.8 & $5 \%$ & 7 & 0.21 & 0.24 & 0.16 & 0.16 & 0.23 & 0.17 & \\
\hline \multicolumn{2}{|c|}{ Stddev/Avg H-P } & $24 \%$ & $33 \%$ & $45 \%$ & $23 \%$ & $8 \%$ & $32 \%$ & $63 \%$ & $35 \%$ & $>100 \%$ & $72 \%$ & $23 \%$ & $21 \%$ & \\
\hline
\end{tabular}

\& External mixture

\$nternal mixture

is located between 20 and $60^{\circ} \mathrm{N}$ and forcing differences are largest especially at northern mid-latitudes. The highest positive forcings in the northern high latitudes by the GISS and the UIO_GCM models coincide with their relatively high BC loads there. Among all AeroCom models only SPRINTARS suggests a very weak positive total RF, which can be traced back to a relatively small negative sulphate RF and the largest positive cloud sky forcing. This high cloud sky forcing is also found in another SPRINTARS simulation (model C) (Takemura et al., 2005).

The diversity of the all-sky RF among AeroCom models is as large as $73 \%$. This is considerably larger than the diversity in load (24\%), AOD (33\%), absorption optical depth (43\%) and clear-sky RF (35\%). The reasons for the differences in RF among the AeroCom models are the subject of discussion in the following sections. Based on the additional output provided by the AeroCom models, individual steps from emissions to forcing can be diagnosed.

The AeroCom diagnostics include two more parameters that concern changes of the radiation balance due to aerosol present in the atmosphere: "Atmospheric forcing" which accounts for solar absorption of incoming radiation in the atmospheric column - and "surface forcing" which reflects the incoming solar radiation at surface level, which is counterbalanced by other heat fluxes at surface level and is thus important for the hydrological cycle but which is not a good indicator of climate warming. The surface forcing equals the
ToA-RF minus the atmospheric forcing. These are rarely reported in other publications and shall be mentioned here, because they constitute an important element for the regional climate impact of the aerosol. The solar all-sky atmospheric forcing attains a global average of $+0.82 \mathrm{Wm}^{-2}$ and consequently the solar surface forcing is at $-1.02 \mathrm{Wm}^{-2}$. The atmospheric forcing is considerably larger than the ToA-RF for all models. The absolute value of the diversity for the atmospheric forcing is comparable to that of RF. The relative standard deviation is only $21 \%$. An inspection of the individual model values of RF and atmospheric forcing reveals that the two parameters are not correlated. Since atmospheric forcing reflects absorption of shortwave radiation we have also tested correlation with the three major components using the average model values from the Tables 2, 4 and 5. The highest correlation coefficient is found for BC$\mathrm{RF}(r=0.54)$, while correlation with POM-RF $(r=0.05)$ and $\mathrm{SO} 4-\mathrm{RF}(r=0.02)$ is absent. Measurements of the radiation budget changes throughout the column can thus be helpful to better understand the carbonaceous RF component. The Indian Ocean Experiment (INDOEX, Ramanathan et al., 2001 and references therein) showed the importance of absorption by aerosol in the atmospheric column. Their observations show that the local surface forcing $\left(-23 \mathrm{Wm}^{-2}\right)$ was significantly stronger than the local RF at the top of the atmosphere $\left(-7 \mathrm{Wm}^{-2}\right)$. 


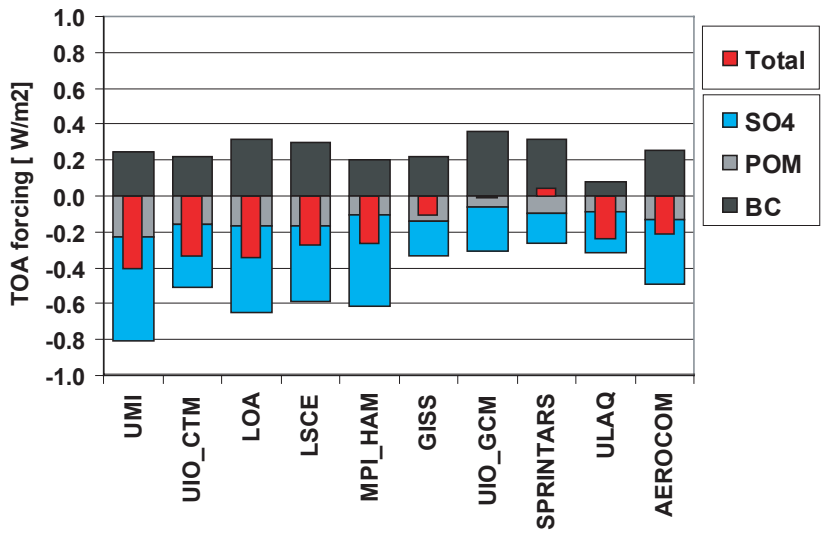

Fig. 2. Direct aerosol forcing for the three major anthropogenic aerosol components sulphate, black carbon and particulate organic matter in the AeroCom models. Shown on top in red is also the total direct aerosol forcing as diagnosed from a full aerosol run.

3.4 Analysis of all-sky, clear-sky and cloud-sky forcing differences

The all-sky solar RF, which was discussed in the previous section, is in addition to parameters that influence clear-sky forcing also modulated by clouds. The clear-sky aerosol RF is influenced by aerosol properties (mainly amount and absorption), by the solar surface albedo and the distribution of water vapor. The presence of cloud changes the radiation field dramatically and can change the sign of aerosol RF. Allsky RF is consequently not just a cloud cover area-weighted clear-sky RF. Therefore we compare here the simulated annual global fields for all-sky (RF) and clear-sky ToA forcing $\left(\mathrm{RF}_{\mathrm{cs}}\right)$ and cloud-sky ToA forcing $\left(\mathrm{RF}_{\mathrm{cl}}\right)$ from the AeroCom simulations as summarized in Table 5. The cloud-sky forcing was not reported by modelers and is recomputed here based on global annual fields of $\mathrm{RF}, \mathrm{RF}_{\mathrm{cs}}$ and individual model derived information on cloud cover $(\mathrm{C})$ :

$\mathrm{RF}_{\mathrm{cl}}=\mathrm{RF} / \mathrm{C}-(1-\mathrm{C}) / \mathrm{C}^{*} \mathrm{RF}_{\mathrm{cs}}$.

Clear-sky RF fields of most of the different AeroCom models in Fig. 4 display similar patterns. Negative forcings are predicted above industrialized zones of the Northern Hemisphere and over tropical biomass burning regions. Positive, or less negative, forcings are simulated over bright desert surfaces and over snow-cover. Larger differences among models over desert regions indicate differences in desert solar albedo assumptions for which we have unfortunately incomplete documentation. The diversity of clear sky-forcing $(35 \%)$ in Table 5 is found to be smaller than that of the all-sky RF (73\%), which reflects better understanding of clear-sky radiative effects.

All-sky (aerosol) annual RF fields of the different AeroCom models in Fig. 5 indicate that the all-sky aerosol RF is almost everywhere less negative than clear-sky forcing

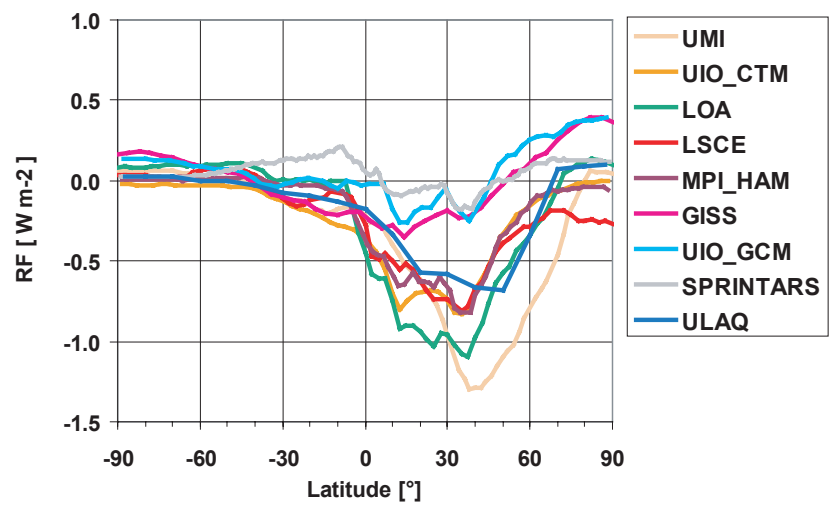

Fig. 3. Zonal distribution of the total direct aerosol forcing for all-skies.

(Fig. 4). Under all-sky conditions, the clear-sky forcing values apply only to cloud-free regions (ca. 30\%), while in conjunction with clouds, aerosol (solar) RF is modulated depending among other parameters on the relative position of aerosol and clouds. If clouds are optically thick and aerosol is below cloud, solar radiation is reflected to a large part back to space, before it can interact with aerosol. RF forcing by aerosol can then be ignored. If aerosol is above clouds, however, the high solar reflectivity of clouds will cause a positive aerosol RF, as observed over surfaces with large solar albedos (e.g. desert, snow). Absorbing aerosol reduces solar reflection to space, which translates into a positive ToA forcing.

We find that the cloud-sky aerosol ToA forcing is a useful diagnostic tool. Cloud-sky annual ToA forcing fields of the different AeroCom models in Fig. 6 display characteristic spatial features, which differ from model to model, and can be linked to physical explanations as found below. The diversity of cloud-sky forcing attains $>100 \%$, due to the uncertainty in sign of this forcing term. The variation in absolute terms, taken into account the large cloudy area fraction, of $\pm 0.16 \mathrm{Wm}^{-2}$ is at least as important as that of the clearsky forcing $\pm 0.24 \mathrm{Wm}^{-2}$ (see Table 5). Globally averaged cloud-sky forcings vary between +0.34 and $-0.16 \mathrm{Wm}^{-2}$ and for almost all models deviate significantly from zero. Since the cloud-covered area is $70 \%$, it dominates over clearsky conditions, and small differences of cloud-sky ToA forcing are an important explanation for the all-sky ToA forcing diversity among the AeroCom models. Global annual averages of $R F, R F_{c s}$ and $R F_{c l}$ are put together in Fig. 7.

Why are models showing positive and negative cloud-sky forcings? An interesting comparison can be made for the LOA and the LSCE model. While the underlying GCM and thus meteorology and transport and emissions are the same, the aerosol dynamics, removal, optical properties and forcing calculations are not. The absolute difference in cloud cover is a result of different diagnostics provided to the AeroCom database. The relative cloud cover distribution is very much 

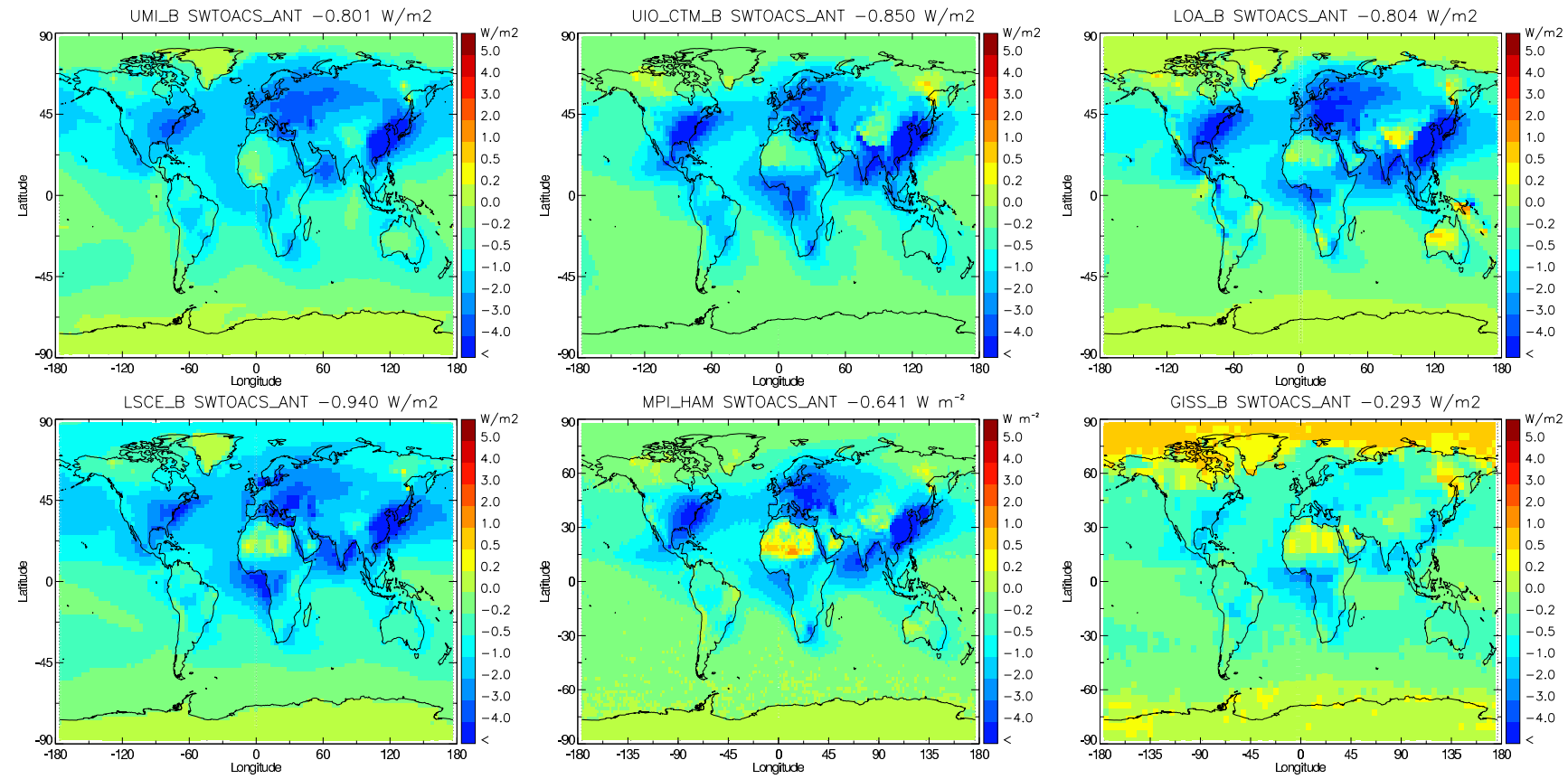

SPRINTARS_B SWTOACS_ANT $-0.358 \mathrm{~W} \mathrm{~m}^{-2}$
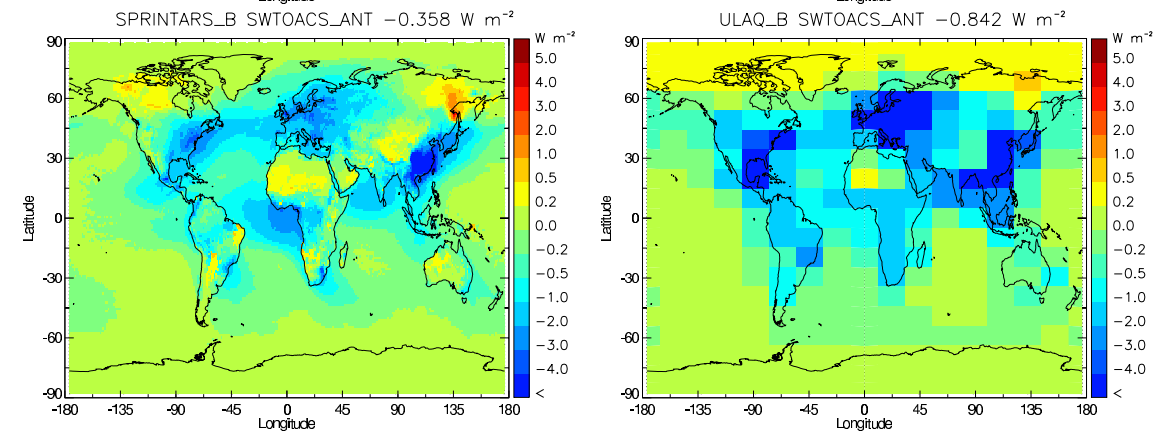

Fig. 4. Maps of the total direct aerosol forcing in clear-sky conditions in the AeroCom models.

alike. We diagnose a negative cloud forcing for LOA and a slightly positive one for LSCE. Clear sky forcing in the LSCE is $20 \%$ more negative. Figure 5 shows similar positive forcing in LOA and LSCE in large regions where absorbing anthropogenic aerosols above marine stratocumulus clouds are responsible for positive cloud-sky forcing. The global average becomes negative for LOA because important negative cloud forcing contributions are diagnosed for North America, Europe and South East Asia. LOA also shows more negative sulphate forcing than LSCE. Higher sulphate AOD in LOA (sulphate AOD LOA:0.35; LSCE: 0.23) can result in more scattering when thin clouds are present and thus produce a negative overall cloud-sky forcing (Zhou et al., 2005).

Looking at all models we find that the three models with the largest negative aerosol all-sky RF also have negative cloud-sky forcings (UIO_CTM, UMI, LOA). Models with low BC loads (UIO_CTM, UMI) do not show positive allsky forcing in any region. Elevated biomass burning aerosol seems to be responsible for positive cloud-sky forcing over the Atlantic off South Africa. UIO_CTM simulates such pos- itive cloud-sky forcing only in the North American and South East Asian polluted areas. While UIO_CTM has a negative cloud sky RF for the annual mean the cloud-sky RF in the biomass burning season (July-September) is positive.

Positive cloud-sky forcings are responsible for the less negative all-sky forcing in LSCE, GISS and SPRINTARS. Note that the model with the largest cloud-sky forcing (SPRINTARS) also simulates the second largest BC loads. MPI_HAM shows similar cloud-sky forcing over the ocean as LOA and LSCE, but simulates important positive contributions also over industrialised mid-latitude regions and above desert areas. This indicates a higher sensitivity of the RF to the albedo - either from bright desert surfaces or clouds. The GISS model shows a small negative all-sky forcing as a combination of the lowest sulphate load and RF and positive cloud-sky forcing in the northern hemisphere, especially over South East Asia and the Pacific. Low all-sky forcing for the UIO_GCM models can in part be explained by low sulphate AOD and high $\mathrm{BC}$ absorption. 

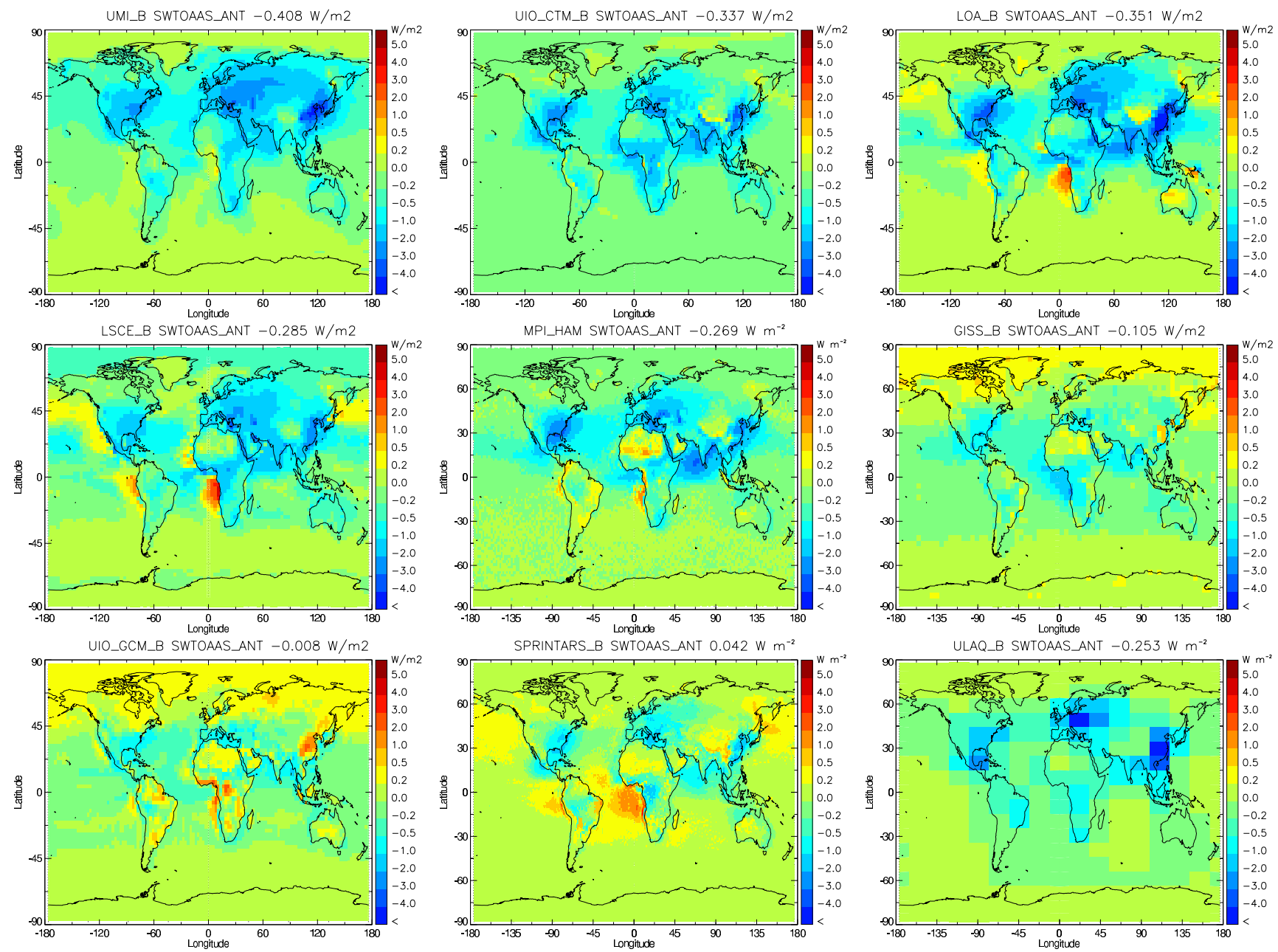

Fig. 5. Same as Fig. 4 but all-sky condition total direct aerosol forcing in the AeroCom models. The ULAQ all-sky forcing is constructed from computed clear-sky forcing, assuming no cloud sky forcing and $70 \%$ cloud cover.

3.5 Sensitivity analysis of major factors linking emission and forcing

Having used identical emissions and analysed meteorology for the same year offers the chance to analyse the different steps from emission to forcing with small interference from large spatial differences in emission and aerosol fields. Few major factors are investigated here for their impact on resulting aerosol forcing diversity among AeroCom models. We neglect to analyse the specific impact on RF of the different environments in the models due to different humidity fields and surface albedo, mainly because we have insufficient diagnostics available. A simplified diagnostic model equation assumes that the RF is a product of emission flux $(E)$, residence time (or life-time) $(t)$, mass extinction efficiency (mass to AOD conversion) (mec) and the radiative forcing efficiency (NRF) with respect to AOD:

$\mathrm{RF}=E * t * m e c * \mathrm{NRF}$.
Since the emissions $E$ are equal, any variability of the three remaining factors ( $t, m e c$, and NRF) influences the simulated forcing. While this is valid for POM, factors of relevance were chosen differently for sulphate, BC and total aerosol. For the total aerosol we introduce the forcing efficiency for clear-sky RF and the ratio of all-sky RF over clear-sky RF as factors. BC RF is related to absorption AOD and a forcing efficiency per unit absorption AOD. Sulphate forcing depends also on the chemical production of aerosol sulphate.

Data from Tables 2, 3, 4 and 5 provide individual residence time, mass extinction coefficient and forcing efficiencies for sulphate, BC and POM and total aerosol. Then for each model $n$, factor $x$ and species $i$ the hypothetical $\mathrm{RF}_{x, n, i}$ (for the case that only the factor $x$ was a source of variability) is defined by $\mathrm{RF}_{x, n, i}=x_{n} /<x>* \mathrm{RF}_{i}$, where $x_{n}$ is the factor value for model $n,\langle x\rangle$ is the AeroCom mean for the factor and $\mathrm{RF}_{i}$ is the mean AeroCom forcing for the aerosol species $i$. 

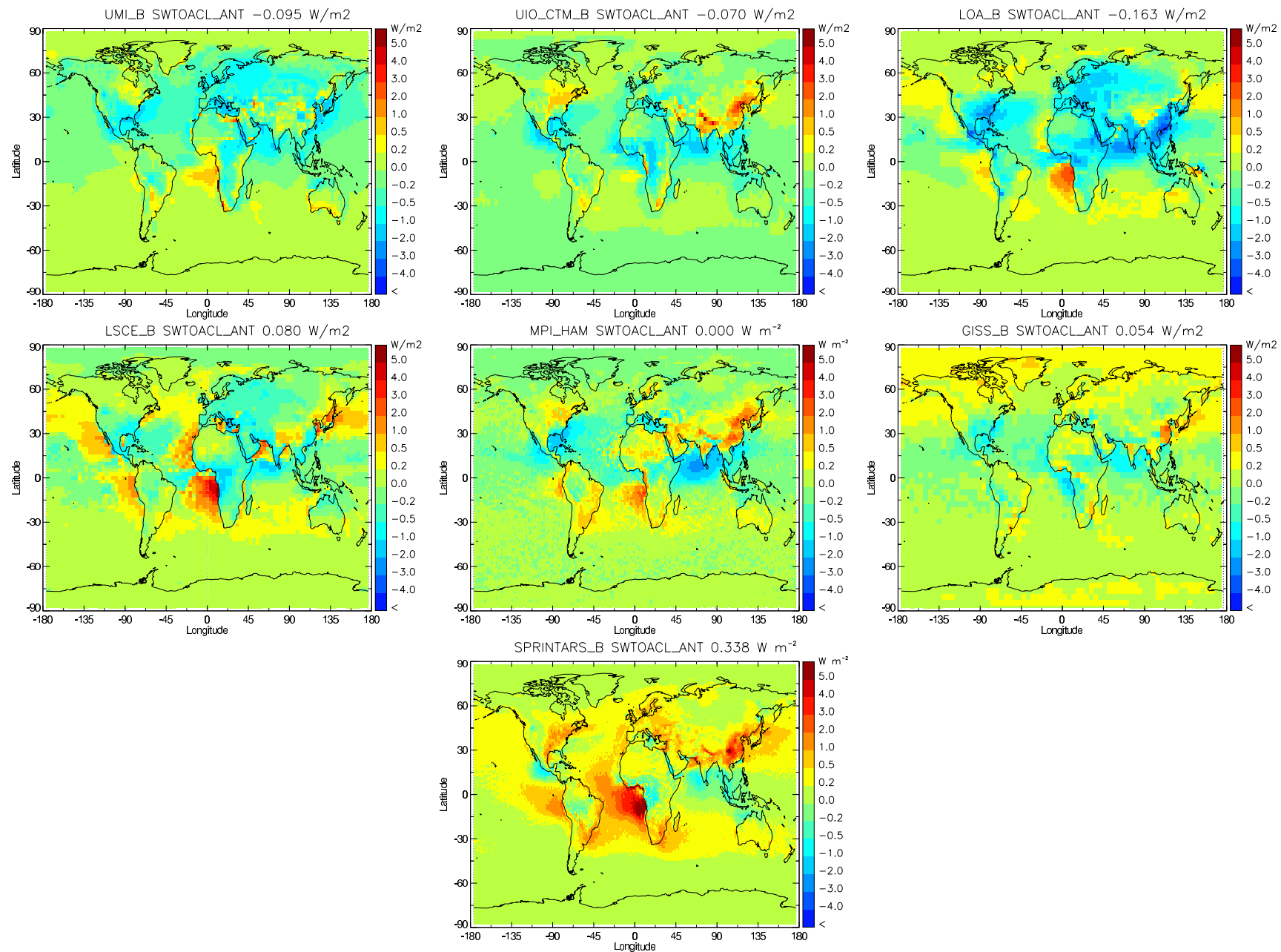

Fig. 6. Same as Fig. 4 but cloud-sky condition total direct aerosol forcing in the AeroCom models.

All $\mathrm{RF}_{x, n, i}$ are presented for each model and factor in Fig. 8 separately for the four species: sulphate, BC, POM and total aerosol. In addition, the original model derived $\mathrm{RF}$ values are shown in the last column. Model specific lines connect estimated $\mathrm{RF}_{x, n, i}$ mainly for readability purposes. Cross-overs indicate compensating effects, which reduce model diversity for the "final" aerosol RF estimate.

The sensitivity for the total anthropogenic forcing in Fig. 8a shows that the clear-sky forcing efficiency and the allsky forcing calculation themselves are responsible for large diversity among the AeroCom models. However, it is probably not so much the radiative transfer calculation method, but differences in composition and most of all the representation of clouds that contribute to the diversity. In comparison, residence time and mass extinction efficiency introduce a relatively small diversity on total RF estimates. Numerous cross-overs indicate that each model has its own way of translating emission into forcing.

The sensitivity of BC forcing in Fig. $8 \mathrm{~b}$ is discussed as a function of the aerosol absorption coefficient. The absorption coefficient based on the global values of absorption and load in Table 3 ranges from $\sim 4.5$ (UMI and LSCE) up to $\sim 10$ (SPRINTARS and UIO_GCM). Note that this is derived from the ratio of anthropogenic absorption and the BC load. It does thus include effects of internal mixing of $\mathrm{BC}$ with other species and eventually from absorption by POM. In contrast to the sensitivity of the total aerosol RF, BC residence time and $\mathrm{BC}$ absorption efficiency cause significant scatter in BC-RF. However, the forcing efficiency remains the major source of diversity. Inspecting the cross-overs of the modelled pathway from emission to forcing reveals much more diverse pathways from emission to BB-RF than those for total aerosol RF.

The sensitivity analysis for POM-RF and sulphate-RF are presented in Figs. 8c and d, respectively. Sulphate residence times together with chemical production constitute a major source of diversity, because formation of sulphate involves additional processes, such as $\mathrm{SO}_{2}$ deposition and chemical production in gas and cloud phase. Interestingly small sulphate residence times (or fast removal) are compensated considerably by high sulphate dry mass extinction coefficients for SPRINTARS, ULAQ, MPI_HAM and UIO_CTM, and 
vice versa for GISS, LSCE and LOA. Since hygroscopic growth is a major factor in enhancing sulphate aerosol extinction one might speculate that larger residence times result from sulphate transported into dry upper air tropospheric layers. This would coincide with little hygroscopic growth and thus would diminish the global extinction coefficient. Inspection of the AeroCom database shows that indeed LOA and LSCE have roughly four times as much sulphate burden located in the upper troposphere $(>5 \mathrm{~km})$ than models like SPRINTARS and UIO_CTM. Diagnosing the vertical distribution of the anthropogenic aerosol water and humidity fields is suggested for future work to give more clarity for this behaviour of the models. Total aerosol water as diagnosed in AeroCom A is dependent on global sea salt loads and is an insufficient diagnostic here.

Different forcing efficiencies for sulphate further seem to complicate the pathway towards forcing. Models with relatively high forcing efficiencies based on sulphate optical thickness are GISS and UMI. Altogether we have to stress that among the four factors influencing the sulphur forcing estimate, none can be called the single major cause of diversity.

POM residence times and extinction coefficients are minor sources of variation. With the exception of SPRINTARS the variation in POM mass extinction coefficient is small. This does not mean that the POM mass extinction coefficient is known well, rather that the models use similar assumptions. A plausible hypothesis is that the models applied the same size distribution as suggested by the AeroCom emission dataset description and that little humidity growth is assumed for the organic particle fraction. For POM we find that the forcing efficiency gives rise to even larger diversity than found in the original forcing estimates in the model output. Due to the lack of diagnostics we cannot verify here all the assumptions made for the POM forcing efficiencies. Internal and external mixing assumptions and absorption properties of the POM may not be as clearly split from the BC as would be needed to clearly understand the diversity in POM forcing efficiency.

\section{Summary and conclusions}

As a summary annual fields averaged from all regridded AeroCom model results are presented in Fig. 9 for anthropogenic aerosol optical depth, the associated RF, the local standard deviation of RF from the nine AeroCom models, solar atmospheric forcing and surface forcing as well as the clear-sky RF.

Anthropogenic aerosol optical depth shows distinct maxima in industrialised regions and above tropical biomass burning regions (Fig. 9a). The prevailing location of the anthropogenic aerosol is over continents. On average anthropogenic aerosol optical depth makes up only $25 \%$ of the total aerosol optical thickness. These two characteristics keep

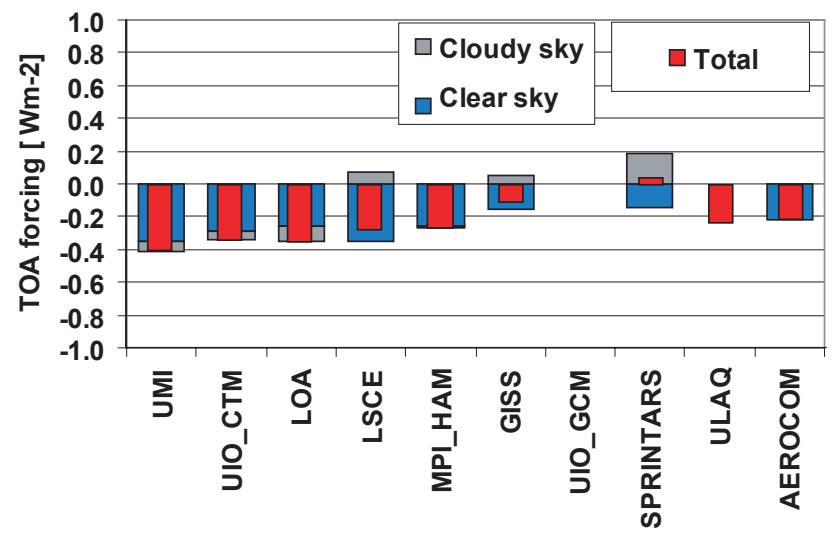

Fig. 7. Total direct aerosol forcing, and contributions from clearsky and cloud-sky conditions. For the latter clear sky and cloud-sky area fractions in each grid box are multiplied with the clear sky and cloud-sky forcing values, so that they add up to the total area weighted all-sky RF.

any comparison with satellite derived aerosol effects a challenging task, since the satellite observations are more reliable over the ocean. Furthermore Fig. 9e shows that the more readily observable clear-sky forcing is dominantly linked to high anthropogenic AOD over the continents. Table 6 compares our work to the recent compilation of observational based RF estimates by Yu et al. (2006), separating AOD, RF and forcing efficiency values between land and ocean. The comparison is also contained to the band between $60^{\circ} \mathrm{S}$ and $60^{\circ} \mathrm{N}$, where satellite observations are abundant and reliable throughout the year. Both AOD and forcing efficiency are lower in the AeroCom models, and consequently the RF is almost twice in the observational based RF. AOD differences in clear sky over the ocean could be attributed to missing anthropogenic aerosol in the models (nitrate, dust, underestimated emission sources), but also any other systematic error in handling the aerosol cycle up to the aerosol optical properties. An overestimation of the anthropogenic fraction of AOD and undetected cloud contamination may be the cause for high satellite retrievals. However, the large difference in clear-sky forcing efficiency over the ocean points to important differences in the clear-sky forcing calculation itself, a problem which is thought to be less difficult to solve than RF over land and in cloud conditions. The more negative forcing based on observational studies driven by satellite retrievals is confirmed by work e.g. from Bellouin et al. (2005) and Kaufman et al. (2005) (RF over ocean $-0.8 \mathrm{Wm}^{2}$ and $-1.4 \mathrm{Wm}^{2}$ ). As long as these differences are not solved we may assume from this comparison, that the model based RF estimate is a low estimate.

The aerosol RF attains $-0.22 \mathrm{Wm}^{-2}$, suggesting in the long term a small impact through aerosol induced climate change on global surface temperature from the presence of anthropogenic aerosol in the atmosphere. General cool- 

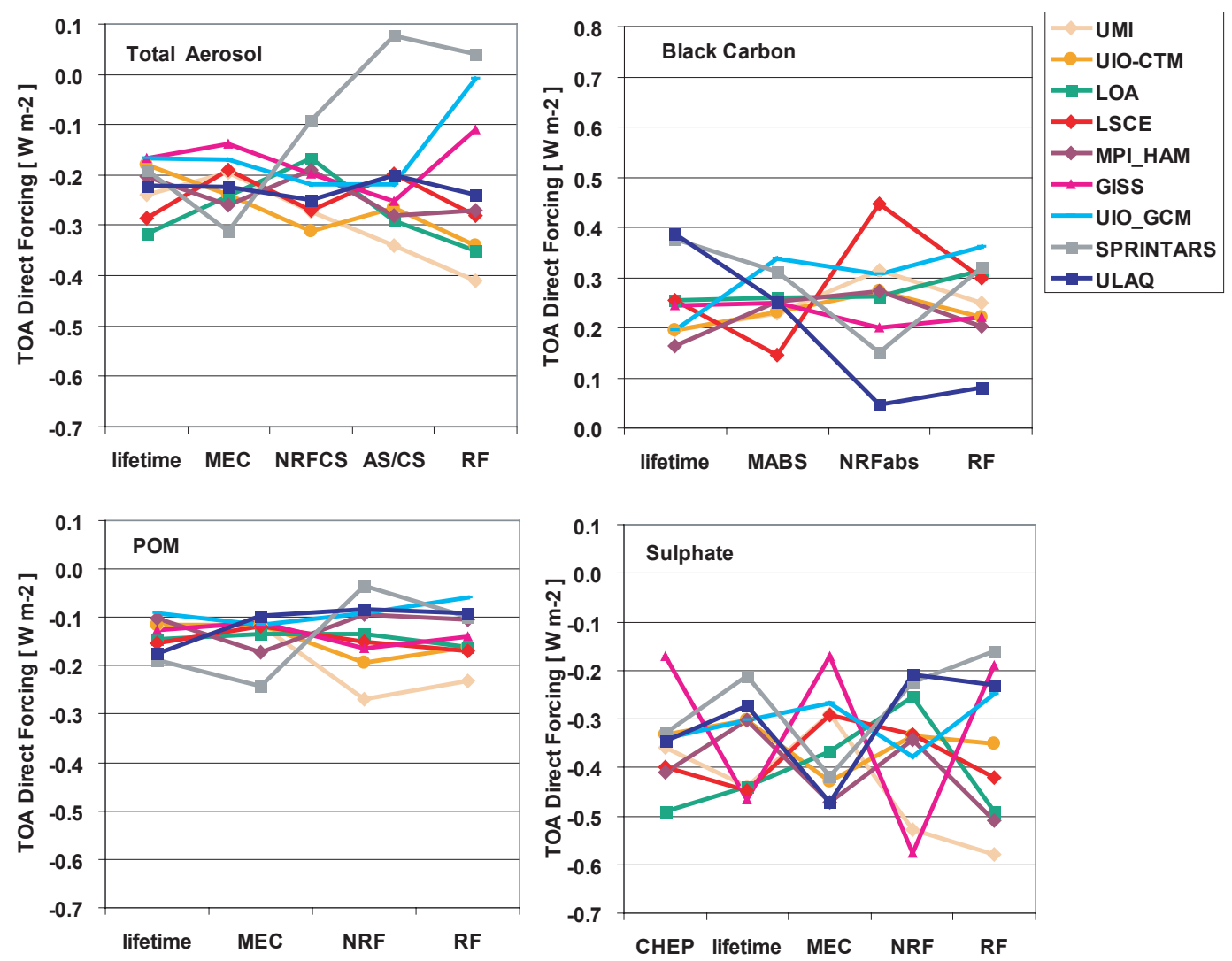

Fig. 8. Partial sensitivity of aerosol forcing to variation in different factors $x$ (see below) of the total anthropogenic aerosol and components in AeroCom models. Shown are recalculated forcings $\mathrm{F}_{x, n}=x_{n} /<x>*<\mathrm{RF}>$; with $x_{n} /<x>$ being the ratio of factor $x$ of model n over its respective AeroCom mean $<x>$; and with $<\mathrm{RF}>$ being the mean AeroCom aerosol or component forcing. For absolute values refer to Tables 2-5. Factors $x$ explanations: "CHEP" ratio of sulphate chemical production over emission of $\mathrm{SO}_{2}$; "lifetime": residence time in the atmosphere; "MEC": Dry mass extinction coefficient; "MABS": BC aerosol absorption coefficient; "NRF": Normalised radiative forcing per unit optical depth; "NRFabs" Normalised radiative forcing per unit absorption optical depth; "NRFCS": Normalised clear-sky radiative forcing per unit optical depth; "AS/CS": All-sky over clear-sky RF ratio; "RF"-column: represents original total aerosol or aerosol component forcing in each of the AeroCom models.

ing over the industrial regions of the northern hemisphere is partly offset by warming over desert regions in the subtropics and when biomass burning aerosol is present over oceanic low stratocumulus regions (Fig. 9b). A regional analysis of the diversity among models can be found in Fig. 9c. The local standard deviation of RF, based on the local annual averages of the nine AeroCom models, suggests that resolving the differences between the models should involve dedicated studies in four regions: South East Asia, African biomass burning areas, the European plume reaching out over the Eurasian continental area and the plume from Eastern North America going to the Atlantic. The local model diversity computed as standard deviation can reach $3 \mathrm{Wm}^{-2}$ in certain regions. This is an order of magnitude above the average RF. The large standard deviations for RF occur whenever models cannot agree on the sign of the cloud-sky forcing. The average local standard deviation, provided at $\pm 0.27 \mathrm{Wm}^{-2}$, is larger than the standard deviation based on annual global averages of $\pm 0.16 \mathrm{Wm}^{-2}$ as presented in Table 5 . This indicates that there is significant spatial variability in model diversity.

While quite some of the factors responsible for the diversity in RF are not at hand in the AeroCom database, we can map the mean dry mass extinction coefficient (MEC) for the anthropogenic aerosol and the clear-sky forcing efficiency and their respective local standard deviations (see Figs. 10ad). The map of MEC shows high mass extinction coefficients in the plumes leaving the American and Eurasian continent. High humidity and a dominance of sulphate is responsible for this pattern. Interestingly this type of aerosol is also visible over much of Europe, indicating considerable humidity growth being present also over the continent. The local diversity in MEC (Fig. 9c) shows a similar pattern than that of the MEC itself. In regions where the anthropogenic aerosol is 
a)

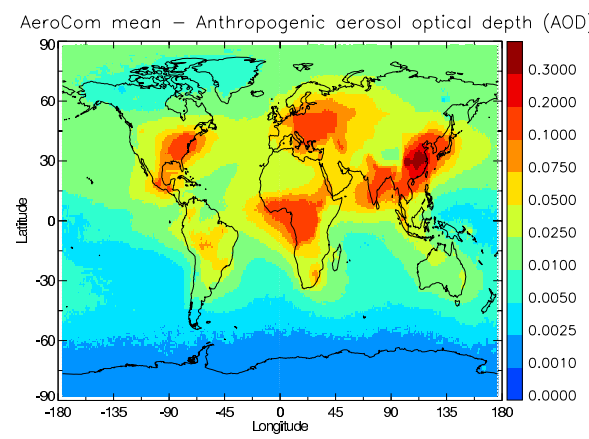

d)

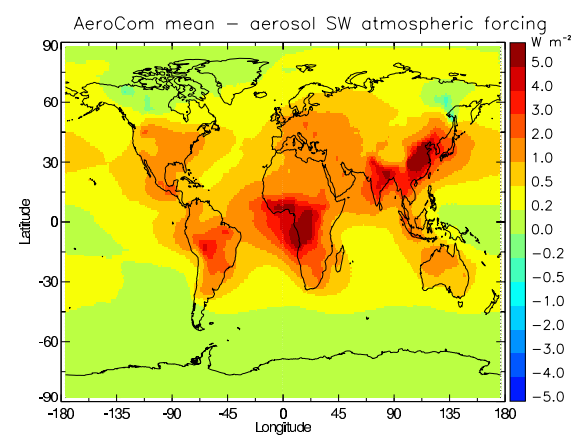

b)

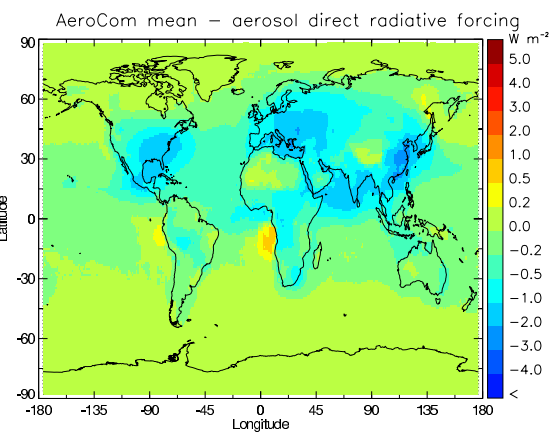

e)

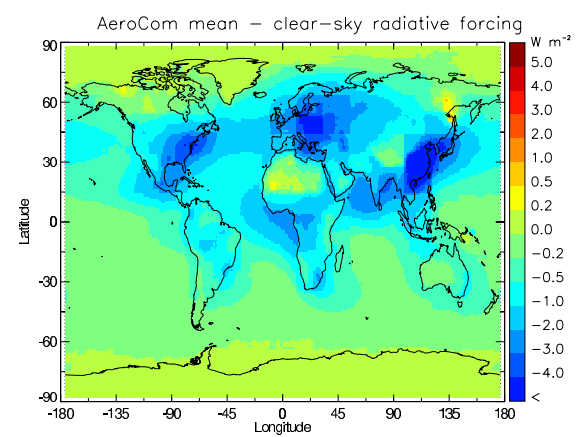

c)

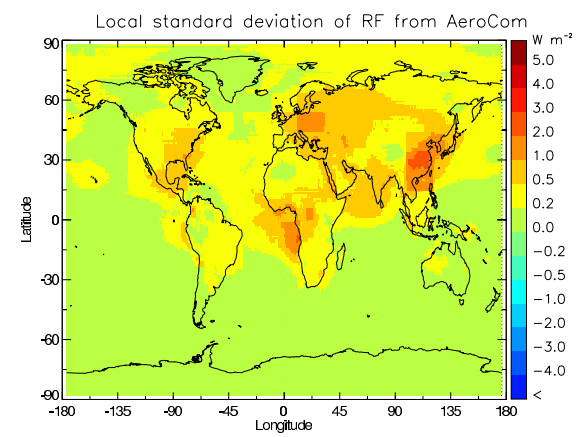

f)

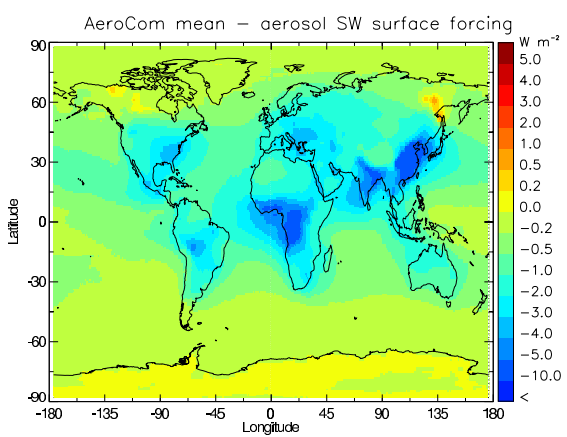

Fig. 9. Mean annual fields derived from the regridded AeroCom model simulations of (a) anthropogenic aerosol optical depth; (b) radiative forcing (c) local standard deviation from 9 models of RF (d) atmospheric forcing of column; (e) clear-sky RF; (f) surface forcing. See values in Table 5. Note that the original model information is often on a coarser grid.

Table 6. AeroCom model simulation results of anthropogenic aerosol optical depth $\left(\tau_{\mathrm{aer}}\right)$, top of the atmosphere radiative forcing $(\mathrm{RF})$ and forcing efficiency per unit optical depth (NRF). Displayed are grid box area weighted means over land and ocean in clear-sky conditions. For comparability with Yu et al. (2006), these values are computed only for the region between $60^{\circ} \mathrm{S}$ and $60^{\circ} \mathrm{N}$, where satellite observations are available. Values from Yu et al. (2006) refer to its Table 19.

\begin{tabular}{lcccccc}
\hline Model & $\begin{array}{c}\tau \\
\text { aer } \\
\text { ocean }\end{array}$ & $\mathrm{RF}$ & $\mathrm{NRF}$ & $\begin{array}{c}\tau_{\text {aer }} \\
\text { land }\end{array}$ & $\mathrm{RF}$ & $\mathrm{NRF}$ \\
\hline UMI & 0.019 & -0.68 & -38 & 0.057 & -1.33 & -24 \\
UIO_CTM & 0.018 & -0.69 & -45 & 0.058 & -1.64 & -28 \\
LOA & 0.033 & -0.67 & -16 & 0.093 & -1.47 & -14 \\
LSCE & 0.025 & -0.89 & -34 & 0.064 & -1.35 & -21 \\
MPI_HAM & 0.023 & -0.57 & -26 & 0.075 & -1.10 & -24 \\
GISS & 0.011 & -0.33 & -38 & 0.026 & -0.42 & -17 \\
SPRINTARS & 0.026 & -0.32 & -11 & 0.081 & -0.63 & -14 \\
\hline AeroCom mean & 0.022 & -0.59 & -29 & 0.065 & -1.14 & -20 \\
Yu et al. 2006 & 0.031 & -1.10 & -37 & 0.088 & -1.80 & -20 \\
AeroCom diversity & $32 \%$ & $35 \%$ & $42 \%$ & $33 \%$ & $40 \%$ & $27 \%$ \\
\hline
\end{tabular}

dominated by biomass burning aerosols, the variation is considerably smaller. This together suggests that the difference in simulated humidity growth of the anthropogenic aerosol plays an important role in the overall diversity of MEC.
The mean forcing efficiency in clear-sky conditions per unit optical depth (NRF) (Fig. 10b) is positive over deserts. Over ocean it is widely negative and most often more negative than $-20 \mathrm{Wm}^{2}$. The presence of absorbing aerosols over 
a)

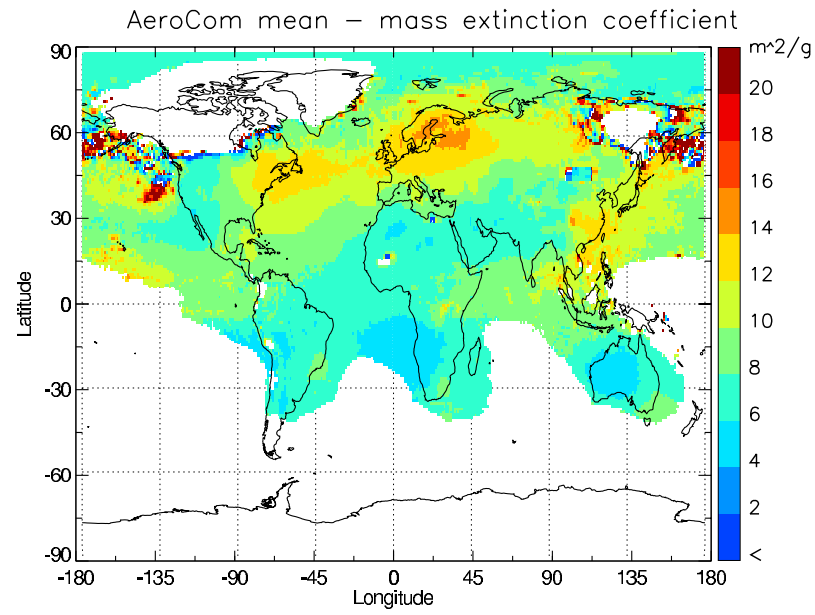

c)

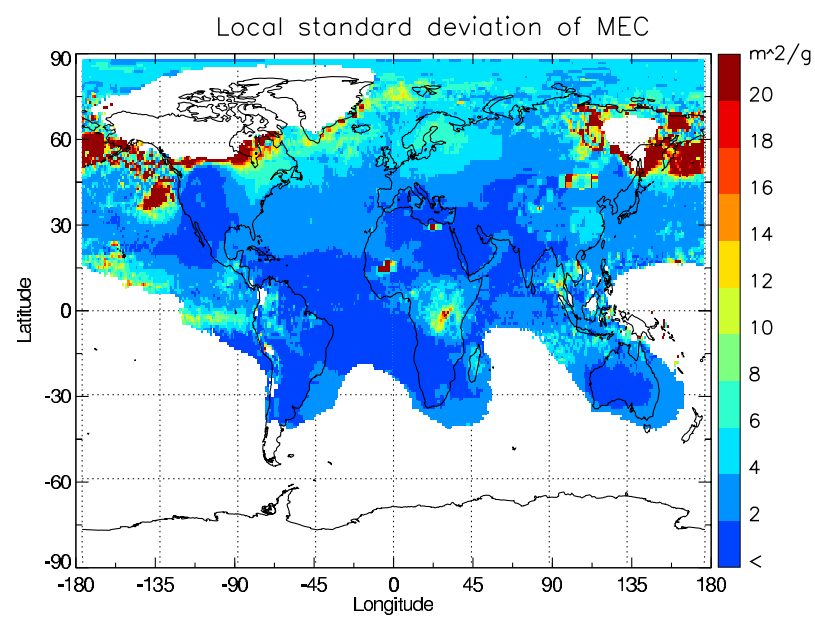

b)

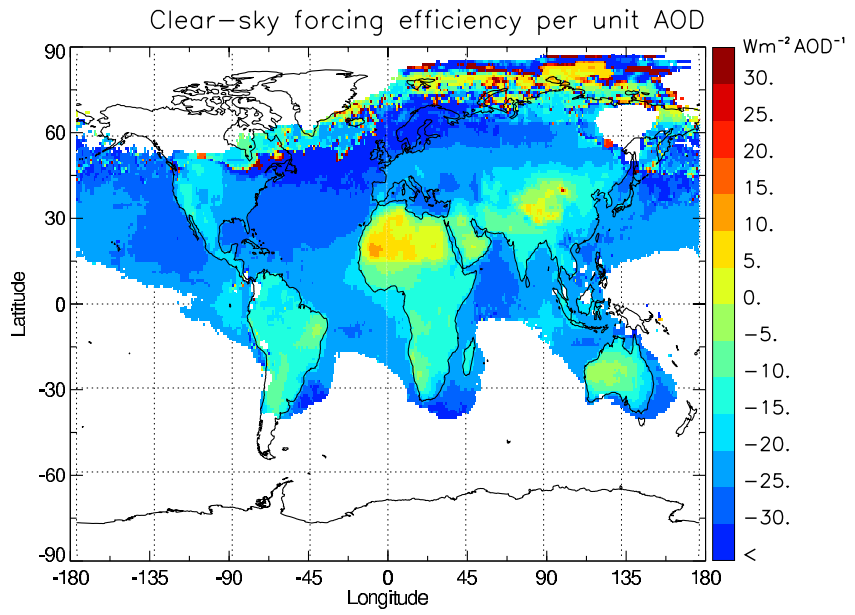

d)

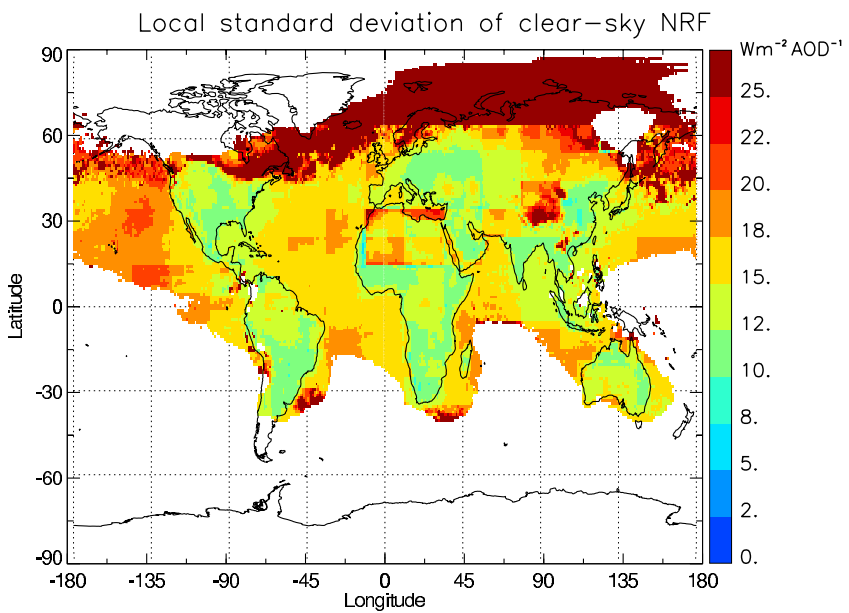

Fig. 10. Mean annual fields derived from the regridded AeroCom model simulations of (a) anthropogenic aerosol mass extinction coefficient, based on dry mass; (b) clear-sky radiative forcing efficiency per unit optical depth (c) and (d) local standard deviation from 8 models excluding UIO GCM for clear sky forcing efficienct. Mean and standard deviation were only computed where the anthropogenic aerosol optical depth exceeded 0.01 .

continents, especially where carbonaceaous aerosol dominate, lowers the negative forcing efficiency. Different assumptions in the northern polar regions of snow and ice albedo are responsible for varying and localised changes in sign of the forcing efficiency and should not be regarded as significant. Local diversity in NRF in these regions is thus also very large (Fig. 10d). In the other areas the local variation of NRF is in magnitude almost as large as the values of NRF itself. Higher diversity among models is found over ocean than over land except for desert regions. Over ocean this points to important differences in the forcing calculation itself and factors such as the asymmetry parameter. Diversity of NRF over deserts can be best explained by differences in surface albedo assumption, which would be desirably better characterised in future work.
The solar atmospheric aerosol forcing, characterizing solar absorption by aerosol, displays local maxima over tropical biomass burning regions and over South East Asia, which can be as large as $+5 \mathrm{Wm}^{-2}$ on an annual basis (Fig. 9d). The local impact of the atmospheric aerosol forcing for changes in the surface energy budget can be deduced from Fig. 9f. The map of surface forcing also illustrates that this aerosol effect is not colocated with the RF at the top of the atmosphere. Given the correlation of $\mathrm{BC}-\mathrm{RF}$ and atmospheric forcing we suggest that places of large atmospheric forcing and larger corresponding surface forcing are preferred locations for a validation of the absorbing component in the models, and for field experiments.

Our sensitivity studies show that model diversity for residence time and calculated optical properties contribute sig- 
nificantly at times to the diversity of the simulated RF. More model data analysis needs to be done to understand the differences. The largest aerosol RF uncertainties are introduced when the modulating effect of clouds needs to be considered in all-sky simulations. A proper representation of cloud fields and the correct relative altitude placement between aerosol and clouds are needed.

To make advances on source attribution, experiments are needed that can identify more unambiguously the contributions of absorbing aerosols from specific source categories. The split in POM and BC from fossil fuel and biomass burning proves to be difficult, especially if model experiments are missing to separate these. If the overall effect of carbonaceous aerosols were known, then the opposing effects of absorbing BC and reflecting POM compounds would be better constrained. The sensitivity of the cloud-sky forcing to absorbing aerosol components adds motivation to focus on carbonaceous aerosols.

The contribution of uncertainty in emissions will directly translate into additional uncertainty of RF. We can only cite here some work, which estimate a range for actual emissions to indicate this uncertainty: Haywood and Boucher (2000) estimated the anthropogenic $\mathrm{SO}_{2}$ emissions to range between 67 and $92 \mathrm{TgS} \mathrm{yr}^{-1}$. Emissions of primary organic carbon from fossil fuel burning have been estimated to be 10 to $30 \mathrm{Tg} \mathrm{Cyr}^{-1}$ (Liousse et al., 1996; Cooke et al., 1999; Scholes and Andreae, 2000). Bond et al. (2004) recently suggested that contained burning (approximately the sum of fossil-fuel and biofuel) emissions are in the range 5$17 \mathrm{TgC}^{-1}$. The formation of secondary organic aerosols is a field with considerable uncertainty (Kanakidou et al., 2005). The variation of emissions as used in the AeroCom A simulations (the original models) provide another - low estimate of emission uncertainty. Textor et al. (2006) found that these varied among 16 AeroCom A models by $23 \%$ for $\mathrm{BC}, 26 \%$ for $\mathrm{POM}$ and $22 \%$ for $\mathrm{SO}_{2}$.

In conclusion, for the first time, a suite of global models with complex component aerosol modules has been employed and initialized with identical emissions in terms of component, amount and size and meteorological fields for the same year. Based on the combination of simulations with nine different models a new estimate of aerosol direct radiative ToA forcing (without nitrate and dust) has been determined at $-0.22 \mathrm{Wm}^{-2}$ with an associated standard deviation of $\pm 0.16 \mathrm{Wm}^{-2}$. This suggests that the direct aerosol effect is small and negative (despite the potential for positive RF by absorbing aerosols especially over bright surfaces). This suggests that on a global annual basis the direct aerosol ToA forcing is opposite in sign and one order of magnitude smaller than the RF attributed to anthropogenic greenhouse gases. However, the atmospheric forcing $\left(+0.82 \mathrm{Wm}^{-2}\right)$ and the surface forcing $\left(-1.02 \mathrm{Wm}^{-2}\right)$ are considerably larger than the top-of-the atmosphere RF. Locally we can expect significant radiative effects which reduce incoming radiation due to anthropogenic aerosols, especially over industrial regions of the northern hemisphere, in particular Southeast Asia, and over tropical regions during biomass burning seasons. Important changes to the hydrological cycle can be expected from such local changes in the radiation budget due to aerosols. Aerosols will enhance greenhouse gas warming over regions with high solar surface albedo (e.g. desert and snow-covered terrain) and when tropical region biomass burning aerosol is advected over low clouds. The overall spread of the models with respect to the different forcing components, both globally and locally, is considerable. Furthermore the harmonised AeroCom emissions did not reduce model diversity to any detectable degree with respect to total AOD for sulphate and POM, and between AeroCom RF results and recently published studies. Harmonized emissions are an idealisation and the estimated RF diversity derived from the AeroCom simulations can be regarded as a minimum estimate for uncertainty in aerosol RF. With the current uncertainties in the modelling of the radiative forcing due to the direct aerosol effect we show that an estimate from one model is not sufficient but a combination of several model estimates is a more adapt procedure to provide a mean and to explore the uncertainty.

Acknowledgements. This work was among others supported by the European Project PHOENICS (Particles of Human Origin Extinguishing "natural" solar radiation In Climate Systems) under grant EVK2-CT-2001-00098. The authors would like to thank the Laboratoire des Sciences du Climat et de l'Environnement/IPSL, Gif-sur-Yvette, France, and the Max-Planck-Institut für Meteorologie, Hamburg, Germany for support in hosting the AeroCom database. The three anonymous reviewers are thanked for a very careful reading and constructive suggestions.

Edited by: V. Fomichev

\section{References}

Adams, P. J., Seinfeld, J. H., Koch, D., Mickley, L., and Jacob, D.: General circulation model assessment of direct radiative forcing by the sulphate-nitrate-ammonium-water inorganic aerosol system, J. Geophys. Res.-Atmos., 106(D1), 1097-1111, 2001.

Anderson, T. L., Charlson, R. J., Schwartz, S. E., Knutti, R., Boucher, O., Rodhe, H., and Heintzenberg, J.: Climate forcing by aerosols - a hazy picture, Science, 300(5622), 1103-1104, 2003.

Balkanski, Y., Schulz, M., Claquin, T., and Guibert, S.: Reevaluation of mineral aerosol radiative forcings suggests a better agreement with satellite and AERONET data, Atmos. Chem. Phys. Discuss.,6, 8383-8419, 2006.

Bauer S. E. and Koch, D.: Impact of heterogeneous sulphate formation at mineral dust surfaces on aerosol loads and radiative forcing in the Goddard Institute for Space Studies general circulation model, J. Geophys. Res., 110, D17202, doi:10.1029/2005JD005870, 2005.

Barrie, L., Yi, Y., Lohmann, U., Leaitch, W. R., Kasibhatla, P., Roelofs, G.-J., Wilson, J., McGovern, F., Benkovitz, C., Meliere, M. A., Law, K., Prospero, J., Kritz, M., Bergmann, D., 
Bridgeman, C., Chin, M., Christensen, J., Easter, R., Feichter, J., Jeuken, A., Kjellstroem, E., Koch, D., Land, C., and Rasch, P.: A comparison of large scale atmospheric sulphate aerosol models (COSAM): Overview and highlights, Tellus, 53B, 615-645, 2001.

Bellouin, N., Boucher, O., Haywood, J., and Reddy, M. S.: Global estimate of aerosol direct radiative forcing from satellite measurements, Nature, 438(7071), 1138-1141, 2005.

Berglen, T. F., Berntsen, T. K., Isaksen, I. S. A., and Sundet, J. K.: A global model of the coupled sulfur/oxidant chemistry in the troposphere: The sulfur cycle, J. Geophys. Res., 109, D19310, doi:10.1029/2003JD003948, 2004.

Bond, T. C., Streets, D. G., Yarber, K. F., Nelson, S. M., Woo, J., and Klimont, Z.: A technology-based global inventory of black and organic carbon emissions from combustion, J. Geophys. Res., 109, D14203, doi:10.1029/2003JD003697, 2004.

Boucher, O. and Pham, M.: History of sulphate aerosol radiative forcings, Geophys. Res. Lett., 29(9), 22-25, 2002.

Charlson, R. J., Schwartz, S. E., Hales, J. M., Cess, R. D., Coakley, J. A., Hansen, J. E., and Hofmann, D. J.: Climate forcing by anthropogenic aerosols, Science, 255, 423-430, 1992.

Chung, S. H. and Seinfeld, J. H.: Global distribution and climate forcing of carbonaceous aerosols, J. Geophys. Res., 107(D19), 4407, doi:10.1029/2001JD001397, 2002.

Clarke, A. D., Shinozuka, Y., Kapustin, V. N., Howell, S., Huebert, B., Doherty, S., Anderson, T., Covert, D., Anderson, J., Hua, X., Moore II, K. G., McNaughton, C., Carmichael, G., and Weber, R.: Size distributions and mixtures of dust and black carbon aerosol in Asian outflow: Physiochemistry and optical properties, J. Geophys. Res., 109, D15S09, doi:10.1029/2003JD004378, 2004.

Coen, M. C., Weingartner, E., Schaub, D., Hueglin, C., Corrigan, C., Henning, S., Schwikowski, M., and Baltensperger, U.: Saharan dust events at the Jungfraujoch: detection by wavelength dependence of the single scattering albedo and first climatology analysis, Atmos. Chem. Phys., 4, 2465-2480, 2004, http://www.atmos-chem-phys.net/4/2465/2004/.

Cooke, W. F., Liousse, C., Cachier, H., and Feichter, J.: Construction of a $1^{\circ} \times 1^{\circ}$ fossil fuel emission data set for carbonaceous aerosol and implementation and radiative impact in the ECHAM4 model, J. Geophys. Res., 104, 22 137-22 162, 1999.

Dentener, F., Kinne, S., Bond, T., Boucher, O., Cofala, J., Generoso, S., Ginoux, P., Gong, S., Hoelzemann, J., Ito, A., Marelli, L., Penner, J., Putaud, J.-P., Textor, C., Schulz, M., van der Werf, G., and Wilson, J.: Emissions of primary aerosol and precursor gases in the years 2000 and 1750, prescribed data-sets for AeroCom, Atmos. Chem. Phys. , 6, 4321-4344, 2006.

Ghan, S., Laulainen, N., Easter, R., Wagener, R., Nemesure, S., Chapman, E., Zhang, Y., and Leung, R.: Evaluation of aerosol direct radiative forcing in MIRAGE, J. Geophys. Res., 106, 52955316, 2001.

Ghan, S. J., Easter, R. C., Chapman, E. G., Abdul-Razzak, H., Zhang, Y., Leung, L. R., Laulainen, N. S., Saylor, R. D., and Zaveri, R. A.: A physically based estimate of radiative forcing by anthropogenic sulphate aerosol, J. Geophys. Res.-Atmos., 106(D6), 5279-5293, 2001.

Hansen, J., Sato, M., Ruedy, R., Nazarenko, L., Lacis, A., Schmidt, G. A., Russell, G., Aleinov, I., Bauer, M., Bauer, S., Bell, N., Cairns, B., Canuto, V., Chandler, M., Cheng, Y., Del Genio, A.,
Faluvegi, G., Fleming, E., Friend, A., Hall, T., Jackman, C., Kelley, M., Kiang, N., Koch, D., Lean, J., Lerner, J., Lo, K., Menon, S., Miller, R., Minnis, P., Novakov, T., Oinas, V., Perlwitz, Ja., Perlwitz, Ju., Rind, D., Romanou, A., Shindell, D., Stone, P., Sun, S., Tausnev, N., Thresher, D., Wielicki, B., Wong, T., Yao, M., and Zhang, S.: Efficacy of Climate Forcings, J. Geophys. Res., 110, D18104, doi:10.1029/2005JD005776, 2005.

Haywood, J. and Boucher, O.: Estimates of the direct and indirect radiative forcing due to tropospheric aerosols: A review, Rev. Geophys., 38, 513-543, 2000.

Haywood, J., Francis, P., Osborne, S., Glew, M., Loeb, N., Highwood, E., Tanre, D., Myhre, G., Formenti, P., and Hirst, E.: Radiative properties and direct radiative effect of Saharan dust measured by the C-130 aircraft during SHADE: 1. Solar spectrum, J. Geophys. Res., 108, 8577, doi:10.1029/2002JD002687, 2003.

Huebert, B. J., Bates, T., Russell, P. B., Shi, G., Kim, Y. J., Kawamura, K., Carmichael, G., and Nakajima, T.: An overview of ACE-Asia: Strategies for quantifying the relationships between Asian aerosols and their climatic impacts, J. Geophys. Res., 108, ACE 1-1-ACE 1-20, 2003.

IPCC: Climate Change 2001: The Scientific Basis. Contribution of Working Group I to the Third Assessment Report of the Intergovernmental Panel on Climate Change (IPCC), edited by: Houghton, J. T., Ding, Y., Griggs, D. J., Noguer, M., van der Linden, P. J., Dai, X., Maskell, K., and Johnson, C. A., Cambridge University Press, Cambridge, UK, 881 pp., 2001.

Iversen, T. and Seland, O.: A scheme for process-tagged SO4 and BC aerosols in NCAR CCM3: Validation and sensitivity to cloud processes, J. Geophys. Res., 107(D24), 4751, doi:10.1029/2001JD000885, 2002.

Jacobson, M. Z.: Global direct radiative forcing due to multicomponent anthropogenic and natural aerosols, J. Geophys. Res.Atmos., 106(D2), 1551-1568, 2001a.

Jacobson, M. Z.: Strong radiative heating due to the mixing state of black carbon in atmospheric aerosols, Nature, 409, 695-697, 2001 b.

Kanakidou, M., Seinfeld, J. H., Pandis, S. N., et al.: Organic aerosol and global climate modelling: a review, Atmos. Chem. Phys., 5, 1053-1123, 2005,

http://www.atmos-chem-phys.net/5/1053/2005/.

Kaufman Y. J., Boucher, O., Tanré, D., Chin, M., Remer, L. A., and Takemura, T.:Aerosol anthropogenic component estimated from satellite data, Geophys. Res. Lett., 32, L17804, doi:10.1029/2005GL023125, 2005.

Kaufman, Y. J., Tam, D., Dubovik, O., Karnieli, A., and Remer, L. A.: Absorption of sunlight by dust as inferred from satellite and ground-based remote sensing, Geophys. Res. Lett., 28, 14791482, 2001.

Kiehl, J. T., Schneider, T. L., Rasch, P. J., Barth, M. C., and Wong, J. : Radiative forcing due to sulphate aerosols from simulations with the National Center for Atmospheric Research Community Climate Model, Version 3, J. Geophys. Res.-Atmos., 105(D1), 1441-1457, 2000.

Kinne, S., Schulz, M., Textor, C., Guibert, S., Balkanski, Y., Bauer, S. E., Berntsen, T., Berglen, T. F., Boucher, O., Chin, M., Collins, W.,Dentener, F., Diehl, T., Easter, R., Feichter, J., Fillmore, D., Ghan, S., Ginoux, P., Gong, S., Grini, A., Hendricks, J., Herzog, M., Horowitz, L., Isaksen, I., Iversen, T., Kirkevåg, A., Kloster, S., Koch, D., Kristjansson, J. E., Krol, M., Lauer, A., Lamarque, 
J. F., Lesins, G., Liu, X., Lohmann, U., Montanaro, V., Myhre, G., Penner, J., Pitari, G., Reddy, S., Seland, O., Stier, P., Takemura, T., and Tie, X.: An AeroCom initial assessment optical properties in aerosol component modules of global models, Atmos. Chem. Phys., 6, 1815-1834, 2006,

http://www.atmos-chem-phys.net/6/1815/2006/.

Kirkevag, A. and Iversen, T.: Global direct radiative forcing by process-parameterized aerosol optical properties, J. Geophys. Res.-Atmos., 107(D20), 4433, doi:10.1029/2001JD000886, 2002.

Kirkevåg, A., Iversen, T., Seland, O., and Kristjansson, J. E.: Revised schemes for optical parameters and cloud condensation nuclei in CCM-Oslo, Institute Report Series No. 128, Section for Meteorology and Oceanography, Department of Geosciences, Oslo, Norway, 2005.

Koch, D.: Transport and direct radiative forcing of carbonaceous and sulphate aerosols in the GISS GCM, J. Geophys. Res.Atmos., 106(D17), 20311-20 332, 2001.

Koch, D., Schmidt, G. A., and Field, C.: Sulfur, sea salt and radionuclide aerosols in GISS, ModelE, J. Geophys. Res., 111, D06206, doi:10.1029/2004JD005550, 2006.

Liao, H., Seinfeld, J. H., Adams, P. J., and Mickley, L. J.: Global radiative forcing of coupled tropospheric ozone and aerosols in a unified general circulation model, J. Geophys. Res.-Atmos., 109(D16), D16207, doi:10.1029/2003JD004456, 2004.

Liao, H. and Seinfeld, J.: Global impacts of gas-phase chemistryaerosol interactions on direct radiative forcing by anthropogenic aerosols and ozone, J. Geophys. Res., 110(D18), D18208, doi:10.1029/2005JD005907, 2005.

Liepert, B. G., Feichter, J., Lohmann, U., and Roeckner, E.: Can aerosols spin down the water cycle in a warmer and moister world?, Geophys. Res. Lett., 31(6), L06207, doi:10.1029/2003GL019060, 2004.

Liousse, C., Penner, J. E., Chuang, C., Walton, J. J., Eddleman, H., and Cachier, H.: A global three-dimensional model study of carbonaceous aerosols, J. Geophys. Res., 101, 19411-19432, 1996.

Liu, X., Penner, J. E., and Herzog, M.: Global simulation of aerosol dynamics: Model description, evaluation, and interactions between sulphate and nonsulphate aerosols, J. Geophys. Res., 110(D18), D18206, doi:10.1029/2004JD005674, 2005.

Liu, X. and Penner, J. E.: Effect of Mt. Pinatubo H2SO4/H2O aerosol on ice nucleation in the upper troposphere using a global chemistry and transport model (IMPACT), J. Geophys. Res., 107, 4141, doi:10.1029/2001JD000455, 2002.

Mahowald, N. M., Rivera, G. C., and Luo, C.: Comment on Tegen et al. 2004, on the "Relative importance of climate and land use in determining present and future global soil dust emissions", Geophys. Res. Lett., 31, L24105, doi:10.1029/2004GL021272, 2004.

Mahowald, N. M. and Luo, C.: A less dusty future?, Geophys. Res. Lett., 30(17), 1903, doi:10.1029/2003GL017880, 2003.

Martin, S. T., Hung, H. M., Park, R. J., Jacob, D. J., Spurr, R. J. D., Chance, K. V., and Chin, M.: Effects of the physical state of tropospheric ammonium-sulphate-nitrate particles on global aerosol direct radiative forcing, Atmos. Chem. Phys., 4, 183214, 2004 http://www.atmos-chem-phys.net/4/183/2004/.

Menon, S., Hansen, J., Nazarenko, L., and Luo, Y. F.: Climate effects of black carbon aerosols in China and India, Science, 297(5590), 2250-2253, 2002.

Ming, Y., Ramaswamy, V., Ginoux, P. A., and Horowitz, L. W.: Direct Radiative Forcing of Anthropogenic Organic Aerosol, J. Geophys. Res., 110, D20208, doi:10.1029/2004JD00553, 2005.

Moulin, C. and Chiapello, I.: Evidence of the control of summer atmospheric transport of African dust over the Atlantic by Sahel sources from TOMS satellites (1979-2000), Geophys. Res. Lett., 31, L02107, doi:10.1029/2003GL018931, 2004.

Myhre, G., Berntsen, T. K., Haywood, J. M., Sundet, J. K., Holben, B. N., Johnsrud, M., and Stordal, F.: Modelling the solar radiative impact of aerosols from biomass burning during the Southern African Regional Science Initiative (SAFARI-2000) experiment, J. Geophys. Res., 108, 8501, doi:10.1029/2002JD002313, 2003.

Myhre, G., Stordal, F., Berglen, T. F., Sundet, J. K., and Isaksen, I. S. A.: Uncertainties in the radiative forcing due to sulphate aerosols, J. Atmos. Sci., 61(5), 485-498, 2004.

Pitari, G., Mancini, E., Rizi, V., and Shindell, D. T. : Impact of future climate and emissions changes on stratospheric aerosols and ozone, J. Atmos. Sci., 59, 414-440, 2002.

Ramanathan, V., Crutzen, P. J., Lelieveld, J., Mitra, A. P., Althausen, D., Anderson, J., Andreae, M. O., Cantrell, W., Cass, G. R., Chung, C. E., Clarke, A. D., Coakley, J. A., Collins, W. D., Conant, W. C., Dulac, F., Heintzenberg, J., Heymsfield, A. J., Holben, B., Howell, S., Hudson, J., Jayaraman, A., Kiehl, J. T., Krishnamurti, T. N., Lubin, D., McFarquhar, G., Novakov, T., Ogren, J. A., Podgorny, I. A., Prather, K., Priestley, K., Prospero, J. M., Quinn, P. K., Rajeev, K., Rasch, P., Rupert, S., Sadourny, R., Satheesh, S. K., Shaw, G. E., Sheridan, P., and Valero, F. P. J.: Indian Ocean experiment: An integrated analysis of the climate forcing and effects of the great Indo-Asian haze, J. Geophys. Res., 106, 28 371-28 398, 2001.

Ramaswamy, V., Boucher, O., Haigh, J. D., Hauglustaine, D. A., Haywood, J. M., Myhre, G., T. Nakajima, Shi, G. Y., and Solomon, S. : Radiative forcing of climate change, in: Climate Change 2001: The Scientific Basis, Contribution of Working Group I to the Third Assessment Report of the Intergovernmental Panel on Climate Change, edited by: Houghton, J. T., Ding, Y., Griggs, D. J., Noguer, M., van der Linden, P. J., Dai, X., Maskell, K., and Johnson, C. A., Cambridge University Press, Cambridge, UK, 349-416, 2001.

Reddy, M. S. and Boucher, O. : A study of the global cycle of carbonaceous aerosols in the LMDZT general circulation model, J. Geophys. Res., 109(D14), D14202, doi:10.1029/2003JD004048, 2004.

Reddy, M. S., Boucher, O., Balkanski, Y., and Schulz, M.: Aerosol optical depths and direct radiative perturbations by species and source type, Geophys. Res. Lett., 32, L12803, doi:10.1029/2004GL021743, 2005a.

Reddy, M. S., Boucher, O., Bellouin, N., Schulz, M., Balkanski, Y., Dufresne, J. L., and Pham, M.: Estimates of global multicomponent aerosol optical depth and direct radiative perturbation in the Laboratoire de Meteorologie Dynamique general circulation model, J. Geophys. Res.-Atmos., 110(D10), D10S16, doi:10.1029/2004JD004757, 2005b.

Scholes, M. and Andreae, M. O.: Biogenic and Pyrogenic Emissions from Africa and their Impact on the Global Atmosphere, Ambio, 29, 23-29, 2000.

Stanhill, G. and Cohen, S.: Global dimming: a review of the evi- 
dence for a widespread and significant reduction in global radiation with discussion of its probable causes and possible agricultural consequences, Agric. Forest Meteorol., 107(4), 255-278, 2001.

Stier, P., Feichter, J., Kinne, S., Kloster, S., Vignati, E., Wilson, J., Ganzeveld, L., Tegen, I., Werner, M., Balkanski, Y., Schulz, M., Boucher, O., Minikin, A., and Petzold, A.: The aerosolclimate model ECHAM5-HAM, Atmos. Chem. Phys., 5, 11251156, 2005, http://www.atmos-chem-phys.net/5/1125/2005/.

Stier, P., Seinfeld, J. H., Kinne, S., Feichter, J., and Boucher, O.: Impact of nonabsorbing anthropogenic aerosols on clearsky atmospheric absorption, J. Geophys. Res., 111, D18201, doi:10.1029/2006JD007147, 2006.

Stier, P., Feichter, J., Kloster, S., Vignati, E., and Wilson, J.: Emission-Induced Nonlinearities in the Global Aerosol System: Results from the ECHAM5-HAM Aerosol-Climate Model, J. Climate, 19, 3845-3862, doi:10.1175/JCLI3772, 2006.

Takemura, T., Nakajima, T., Dubovik, O., Holben, B. N., and Kinne, S.: Single-scattering albedo and radiative forcing of various aerosol species with a global three-dimensional model, J. Climate, 15(4), 333-352, 2002.

Takemura, T., Nakajima, T., Nozawa, T., and Aoki, K.: Simulation of future aerosol distribution, radiative forcing, and long-range transport in East Asia, J. Meteorol. Soc. Japan, 79(6), 11391155, 2001.

Takemura, T., Nozawa, T., Emori, S., Nakajima, T. Y., and Nakajima, T.: Simulation of climate response to aerosol direct and indirect effects with aerosol transport-radiation model, J. Geophys. Res.-Atmos., 110, D02202, doi:10.1029/2004JD005029, 2005.

Tegen, I. and Fung, I.: Contribution to the atmospheric mineral aerosol load from land surface modification, J. Geophys. Res., 100, 18 707-18 726, 1995.

Tegen, I., Werner, M., Harrison, S. P., and Kohfeld, K. E.: Relative importance of climate and land use in determining present and future global soil dust emission. Geophys. Res. Lett., 31, L05105, doi:10.1029/2003GL019216, 2004.
Textor, C., Schulz, M., Guibert, S., Kinne, S., Balkanski, Y., Bauer, S., Berntsen, T., Berglen, T., Boucher, O., Chin, M., Dentener, F., Diehl, T., Easter, R., Feichter, H., Fillmore, D., Ghan, S., Ginoux, P., Gong, S., Grini, A., Hendricks, J., Horowitz, L., Huang, P., Isaksen, I., Iversen, T., Kloster, S., Koch, D., Kirkevåg, A., Kristjansson, J. E., Krol, M., Lauer, A., Lamarque, J. F., Liu, X., Montanaro, V., Myhre, G., Penner, J., Pitari, G., Reddy,S., Seland, Ø., Stier, P., Takemura, T., and Tie, X.: Analysis and quantification of the diversities of aerosol life cycles within AeroCom, Atmos. Chem. Phys., 6, 1777-1813, 2006, http://www.atmos-chem-phys.net/6/1777/2006/.

van der Werf, G. R., Randerson, J. T., Collatz, G. J., and Giglio, L.: Carbon emissions from fires in tropical and subtropical ecosystems, Global Change Biol., 9(4), 547-562, 2003.

Wang, C.: A modelling study on the climate impacts of black carbon aerosols, J. Geophys. Res.-Atmos., 109(D3), D03106, doi:10.1029/2003JD004084, 2004.

Yu, H., Kaufman, Y. J., Chin, M., Feingold, G., Remer, L. A., Anderson, T. L., Balkanski, Y., Bellouin, N., Boucher, O., Christopher, S., DeCola, P., Kahn, R., Koch, D., Loeb, N., Reddy, M. S., Schulz, M., Takemura, T., and Zhou, M.: A Review of Measurement-based Assessments of the aerosol direct radiative effect and forcing, Atmos. Chem. Phys., 6, 613-666, 2006, http://www.atmos-chem-phys.net/6/613/2006/.

Zhou, M., Yu, H., Dickinson, R. E., Dubovik, O., and Holben, B. N.: A normalized description of the direct effect of key aerosol types on solar radiation as estimated from Aerosol Robotic Network aerosols and Moderate Resolution Imaging Spectroradiometer albedos, J. Geophys. Res., 110, D19202, doi:10.1029/2005JD005909, 2005. 